Copyright ( $) 2015$ by the Association for Computing Machinery, Inc. (ACM). This is the author's version of the work. It is posted here by permission of ACM for your personal use. Not for redistribution. The definitive version was published in ACM Transactions on Computer-Human Interaction, 22(5) October 2015. http:// doi.acm.org/10.1145/2775107

Citation: Steve Benford, Chris Greenhalgh, Bob Anderson, Rachel Jacobs, Mike Golembewski, Marina Jirotka, Bernd Carsten Stahl, Job Timmermans, Gabriella Giannachi, Matt Adams, Ju Row Farr, Nick Tandavanitj, and Kirsty Jennings. 2015. The ethical implications of HCI's turn to the cultural. ACM Trans. Comput.-Hum. Interact. 22, 5, Article 24 (August 2015), 37 pages.

DOI: http://dx.doi.org/10.1145/2775107 


\title{
The Ethical Implications of HCl's Turn to the Cultural
}

\author{
STEVE BENFORD, CHRIS GREENHALGH, BOB \\ ANDERSON, RACHEL JACOBS, MIKE GOLEMBEWSKI \\ University of Nottingham, UK
}

MARINA JIROTKA, University of Oxford, UK

BERND CARSTEN STAHL, JOB TIMMERMANS

De Montfort University

GABRIELLA GIANNACHI

University of Exeter, UK

MATT ADAMS, JU ROW FARR, NICK TANDAVANITJ, KIRSTY

JENNINGS

Blast Theory, UK

\begin{abstract}
We explore the ethical implications of HCI's turn to the 'cultural'. This is motivated by an awareness of how cultural applications, in our case interactive performances, raise ethical issues that may challenge established research ethics processes. We review research ethics, HCI's engagement with ethics and the ethics of theatrical performance. Following an approach grounded in Responsible Research Innovation, we present the findings from a workshop in which artists, curators, commissioners and researchers explored ethical challenges revealed by four case studies. We identify six ethical challenges for HCI's engagement with cultural applications: transgression, boundaries, consent, withdrawal, data and integrity. We discuss two broader implications of these: managing tensions between multiple overlapping ethical frames; and the importance of managing ethical challenges during and after an experience as well as beforehand. Finally, we discuss how our findings extend previous discussions of Value Sensitive Design in HCI.
\end{abstract}

Categories and Subject Descriptors: H500 [Human-centred computing]: Human Computer Interaction - HCI Theory, Concepts and Models

Additional Key Words and Phrases: Art, Performance; Ethics; Uncomfortable Interactions; Discomfort; Consent; Withdrawal; Boundaries; Transgression; Integrity; Blast Theory; Active Ingredient; Urban Angel; Thrill Laboratory; Research in the Wild.

We gratefully acknowledge the support of the Engineering and Physical Sciences Research Council (EPSRC) through the Horizon Digital Economy Hub (grant EP/G065802); Steve Benford Dream Fellowship (EP/J005215/1); and the Framework for Responsible Research and Innovation (EP/J000019/1). 


\section{INTRODUCTION}

From high-brow art to mainstream entertainment, HCI has been taking a turn to the 'cultural', by which we mean a turn to address a broad swathe of applications of interactive technologies in areas such as art, performance, heritage, visiting and entertainment. Indeed, the digital arts have recently been adopted as a featured community by the $\mathrm{CHI}$ conference (England and Fantauzzacoffin 2013). Much of this research quite rightly focuses on how HCI can practically support this class of emerging applications. What kinds of new interactional challenges do they raise and how can we design for them? However, we must also consider what this turn to the cultural delivers back to $\mathrm{HCI}$ - what new ideas does it throw up and what wider relevance might these have? Here we argue that the turn to the cultural has already inspired new approaches that challenge the tenets of traditional interaction design, for example in promoting ambiguity (Gaver 2003), interpretation (Sengers and Gaver 2006), spectator interfaces (Reeves 2011) and various approaches to designing extended user experience such as sensory threads (McCarthy and Wright 2004) and trajectories (Benford et al 2009), all of which have been grounded in cultural applications.

This paper seeks to open up a further important dimension of the evolving relationship between cultural experiences and HCI - that of ethics. This has arisen from recent work on 'uncomfortable interactions', the idea that one might deliberately employ various forms of discomfort in interaction design - visceral, cultural, interactional and social - in order to deliver powerful experiences that as a result, may be more entertaining, 
enlightening or socially bonding for their participants (Benford et al 2013). This idea of uncomfortable interactions has arisen from a process of reflection across cultural applications of HCI from theatre to theme parks. It has also directly raised the challenge of ethics, especially in relation to responsible research and innovation.

The original paper on uncomfortable interactions touched on the issue of ethics, turning to the history of ethical thought to sketch out some potential justifications for engaging with this approach before briefly highlighting new ethical challenges, especially with regard to consent, withdrawal and privacy. However, this was very much a preliminary discussion, one that raised initial questions but without supplying detailed answers. It is also one that sparked a heated debate among the authors of this paper, initially over email, as we tried to resolve the ethical challenges and underlying values at play.

This discussion felt important to us for three reasons. First, it became clear that HCI's turn to the cultural raises deep ethical questions. There is a long history of consciously confronting ethical issues in the arts and of pushing the boundaries of taste and decency or personal limits in entertainment. These, however, are not yet widely explored in HCI whose discussion of values over recent years has tended to focus on inclusivity, universality, sustainability and peace. HCI's treatments of cultural experiences to date have tended to reflect such values, for example focusing on the role of ecologically-engaged art in sustainable HCI (DiSalvo 2009), or emphasizing what might be thought of as 'positive' aspects of cultural engagement such as aesthetics and emotion (McCarthy and Wright 2004]), ludic playfulness (Morrison et al 2011) and even fun (Blythe et al 2004). However, while HCI may have, for perfectly good reasons, tended to foreground relatively conventional and widely 
recognized values, the arts exhibit something of a tendency to challenge these. Our discussion of uncomfortable interactions revealed that there is other important territory for HCI to explore when addressing cultural experiences, for example recognising the tradition of provoking and confronting difficult, even taboo, subjects and feelings.

Second, researchers across all disciplines, including HCI but also the arts, are increasingly operating within formalized institutional ethical frameworks. Funding bodies and research organisations require ever greater ethical accountability through mechanisms such as ethics committees and review boards, while there is also a growing public awareness of ethical issues, for example around privacy and the treatment of personal data. As we shall argue below, there may be a natural tendency to transfer established ethical frameworks into new disciplines, and the best established are those from biomedical research which address humansubjects experimentation. Concern has already been expressed about the applicability of such models to the social sciences (Murphy 2001; Boulton and Parker 2006) and we anticipate similar issues when trying to apply them when working with creative practitioners such as artists, game designers and ride engineers.

Third, in parallel to this, a novel programme of research concerned with Responsible Research and Innovation (RRI) is emerging across the sciences and technology design that advocates a different kind of relationship between innovations, stakeholders and researchers/innovators (von Schomberg 2013; Grimpe et al 2014) which, as we shall argue, may potentially accommodate disciplinary sensitivities in the treatment of ethical issues - at least in the sense of opening up research directions to a variety of stakeholders including members of the public. 
In short, it is both important and timely to foreground the ethical challenges that arise from HCI's engagement with a variety of cultural experiences. In this paper, we attempt the next step towards this by addressing three key questions:

- What is distinctive about arts-driven research within HCI?

- What ethical challenges does it raise?

- How might we deal with these challenges within the context of RRI?

In answering these questions, our contribution is to try to surface new ethical challenges that HCI needs to consider in its continuing engagement with the cultural; to populate these with a set of examples; and ultimately to propose a novel approach to handling ethics in future projects. Our aim is both to highlight some specific challenges that need to be negotiated by practitioners who are entering this field, and also to help frame the broader nature of HCI's interdisciplinary engagement with the arts.

Our approach to answering these questions was based on that of RRI as described in detail below. Broadly speaking, we sought to bring our initial email discussions out into a more public forum by staging a workshop at which we gathered nearly 40 different stakeholders working at the interface between digital art and HCI, including creative practitioners, $\mathrm{HCI}$ researchers, and arts commissioners and funders, to identify and discuss ethical challenges. This discussion was seeded by four case studies drawn from the complementary creative practices of performance, installation, games, and theme park design, which then stimulated participants to draw on their own extensive experiences. This paper synthesizes this discussion into a set of ethical challenges. 
An exploration of the relationship between HCI, art and ethics has the potential to become very wide-ranging, making it important to delimit our scope of interest. We therefore clarify the kinds of the artworks that we are considering here and discuss their relationship to HCI research before progressing further.

While HCI has a growing engagement with various forms of artistic and cultural experience, our discussion builds on a particular thread of research that has emerged since around the year 2000; one that has recently been characterised as 'performance-led research in the wild' (Benford et al, 2012). To summarise, there has been a series of projects between artists who employ digital technologies to stage live performances and HCI researchers who have provided technical assistance to realize them and who have also conducted naturalistic studies of them 'in the wild' of touring. Critical reflection across multiple performances and studies has revealed new challenges for $\mathrm{HCI}$ and also informed conceptual frameworks (e.g., 'uncomfortable interactions' as noted above) as a form of HCI theory as articulated by Rogers (2012). This current paper is grounded in this approach and represents a further example of critical reflection across a portfolio of artworks so as to draw our wider issues, in this case ones concerned with ethics.

\section{The kinds of performances that we consider}

A focus on digital performance is still somewhat broad. There are many kinds of performance that we might be speaking of: professionally staged affairs in major cultural venues; amateur productions; impromptu social performances among friends; or possibly even the general performance of the everyday self in the sense of Goffman (1959). Our focus here falls on the professional end of the spectrum, meaning performances that are created by professional artists and staged in recognized cultural venues. 
Even then, such performances might still take many forms, leading us to the thorny question of what is a performance - or indeed an artwork anyway?

The history and philosophy of art suggests many potential answers to this question, initially focusing on the representational and then expressive aspects of artworks, before turning to more conceptual and sociological definitions. The advent of modern art in the 20th century and in particular 'readymade' artworks such as Duchamps 'Urinal' and Warhol's 'Brillo Boxes' highlighted the impossibility of identifying an artwork from its observable properties alone. In response, analytic philosophers such as Danto (1964) and then Dickie (1974, 1997) established 'institutional' models of art in which artworks are seen to exist within, and are defined through, artworlds which are comprised of bodies of known ideas or theories of art (Danto's perspective), or else networks of individuals and cultural organisations responsible for creating, exhibiting, critiquing and selling art (Dickie's perspective). The nature of such 'artworlds' was also explored by the sociologist Howard Becker (1982) who described in situ, the interactions between artists and the 'makeweights within the artworld' (to borrow a phrase from Danto's 1964 essay), that is, the galleries, museums, curators, patrons, and other socio-cultural groupings that make artistic practice possible.

Adopting an institutional perspective, we clarify the kinds of performance that we consider here with respect to the particular artworld systems - socio-cultural frameworks for the understanding of artworks within which they are recognised. In our case, we focus on works produced by a network of artists who are primarily based within the UK (although may tour internationally) and who are operating professionally in the sense that they are paid to deliver works to public audiences. Their 
works may sometimes appear in established performance venues, for example London's Royal Opera House or The Barbican (for Blast Theory), but are also to be found in galleries and at digital arts festivals, while others deliberately target more everyday public spaces such as amusement parks or even the city streets. An important element of this particular subset of the artworld is the presence of public funders of art, notably the UK's Arts Council (whose involvement serves to legitimise performances) as well as direct commissions from venues and support from related bodies such as the Arts and Humanities Research Council, a further UK funding body that supports research by both artists and scholars. A final key aspect of this artworld system is its thematic focus on digital technologies. Significantly, these are artists who are exploring how digital devices and interfaces, connected through the Internet, can mediate experience to create new forms of performance in which traditional audiences cross the 'fourth wall' of the conventional theatre to become part of the action; indeed it is this property that underlies many of the ethical challenges that we consider below.

In short, while it is not possible to define the performances we consider from their observable external form or structure - they vary widely and are often deliberately integrated with other forms - we can recognize them as existing within a particular subset of the broader artworld.

\section{The relationship of these performances to $\mathrm{HCl}$ research}

The artworks that we consider below are also part of the world of HCI research, in the sense that HCI researchers have been involved in making and studying them. Thus HCI researchers have become part of the artworld while the artists have in turn become part of the 'HCI world' (recognizable as such by appearing as authors on many research papers published in HCI venues). It is this mixing of artistic practice and HCI research that has 
ultimately driven the emergence of performance-led research in the wild as a distinct approach. Our previous paper identified three main facets of the approach:

1. Practice - referring to artist-led endeavours to create, stage and tour new artworks, during which HCI researchers often provide technical expertise and support;

2. Study - researcher-led endeavours to study how audiences engage with the resulting works and also how the artists deliver them, typically employing naturalistic techniques such as ethnography to engage with performances as they tour.

3. Theory - in which critique and reflection across a number of performances and studies informs new approaches, concepts, paradigms and guidelines of interest to both HCI researchers and artists.

In practice, these activities become highly interleaved as a portfolio of performances and a corpus of studies and reflections is built up over time (see Benford et al, 2012 for detailed mappings). Consequently, it becomes difficult to maintain traditional separations between research and practice. Rather, artistic practice and HCI research become productively conflated and new approaches emerge at the boundaries.

This paper presents the outcomes of a 'theory' activity in the form of a critical reflection across existing projects and studies so as to highlight and explore new challenges and concepts.

Moreover, the focus on ethics has led us to further extend this by drawing on techniques from the emerging field of Responsible Research Innovation which provides frameworks and techniques for engaging with ethical concerns during the process of technology innovation. In our case this has involved adopting an active approach to involving stakeholders in critical and reflective activities as we discuss in greater detail below. 
However, before introducing RRI, we next turn our attention to a review of related work on the nature of ethics in both HCI and performance.

\section{RELATED WORK}

There is of course an extremely long history of ethical thought on which we might draw, including writings on the ethics of art and performance. We therefore first set the scene by reviewing three particular ethical traditions that to some extent collide in this paper. First is the spread of institutional ethics frameworks and processes that provide the broad context and a good part of our motivation for this paper. Second is HCI's history of engagement with ethics in which new ethical challenges have emerged alongside successive generations of technologies, applications and approaches. Third is the distinct ethical history of the arts that stands in some contrast to both of the above.

\section{The rise of institutional research ethics}

Our discussion of ethics in this paper takes place against a broad backdrop of the spread of institutional ethics, by which we mean a growing engagement with research ethics across many different disciplines leading to the introduction of ethical frameworks and their embodiment in ethical processes, committees and review boards. This process first began with the formulation of the Nuremberg Code of ethics following the Nuremberg Trials in 1946 (Annas 1995). It was subsequently driven through responses to scandals such as the Tuskegee Syphilis Experiment (Jones 1993), but then spread to other experimental disciplines such as Psychology, also driven in part by the furore surrounding the Stanford Prison Experiment (Zimbardo 1973]) Consequently, the most widely understood and established ethical frameworks and process are those that 
govern human subjects experimentation - biomedical or psychological that frame research in terms of doing experiments on participants in order to derive important knowledge of wider societal benefit, but also where there may also be serious risks to subjects including ill health or even death

As institutional ethics increasingly spreads into other disciplines, including those that contribute to HCI and the arts, so it is perhaps natural for research organisations to adopt tried and tested approaches. And yet this may be far from appropriate or straight-forward. As an example, the extension of the regulation framework of biomedical research to include social and computer science research is not without its critics. For many social scientists this was seen as an imposition upon research that claimed its own paradigms and corresponding ethical concerns generated by these paradigms (Boulton and Parker 2006). Social scientists challenged the appropriateness and feasibility of the experimental subject model expressing various concerns. The lower order of risk involved in social science research makes the formal consent procedures and research ethics committees appear heavy handed (Kent, Williamson, Goodenough, \& Ashcroft, 2002; Pattullo, 1982; Whittaker, 2005). In addition, the 'anticipatory' nature of consent where issues of concern and risk are identified at the beginning of an investigation are not always desirable in qualitative social science research where such issues themselves may be a matter of enquiry and discovery (Ramcharan \& Cutliffe, 2001; Riessman, 2005). A further concern lies in the potential undermining of the researcher and participant relationship. In these relationships, the trust that is built up is 'earned incrementally' within their developing relationship and the requirement for a signed consent form may frame this relationship in a legalistic way that creates an atmosphere of distrust. It may also establish a 
hierarchical relationship between the researcher and participants that may be inappropriate within some contexts (including the arts and spaces created within the arts that may want to question these hierarchies).

A fundamental critique comes from researchers who challenge the dominant rights-and-justice-based model of ethics that underpins the notion of informed consent in biomedical research and who instead propose virtue-based approaches to bioethics. Here, there is a rejection of the importance given to individuals, universalism and distance as a fundamental basis for the research relationship, and instead encourage an ethical relationship based on particularism, collective rights and active engagement (Denzin, 1997; Edwards \& Mauthner, 2002). These authors argue that formal informed consent procedures are deeply problematic from this viewpoint, where the focus is shifted a) from identifying and eliminating potential risks in advance of the study to engaging actively with the moral dilemmas as they emerge in the course of the investigation; and b) from individualistic concerns to more interpersonal relations.

\section{HCl's engagement with ethics}

Almost from its very beginnings, the HCI community has been concerned with the broader ethical and societal issues of the design and use of computer systems. Debates and discussions about ethics and innovation can be traced to the early 1950s (Wiener 1954), through to the 1980s and 1990s (Ehn 1990, Mumford 1995), the 2000s (Friedman and Khan 2003; Flanagan et al 2005), to the present day (Luger, Moran and Rodden, 2013).

An important early focus for HCI as a field lay in providing what was seen as universal usability and applying scientific research to the design of user interfaces (Knight 2006). Within this remit, research typically focused on improving the interactions between a user and a computer by modeling 
the user's intentions or cognitive processes. In the context of such investigations, a concern arose regarding what may be called 'the professional ethics' of the HCI researcher, referring to the processes of research to safeguard both the investigator and the user as a participant in an investigation. Maintaining the integrity of the research and the researcher subsequently became a key ethical focus for HCI. Friedman (2003) formulates this as encompassing: accountability, autonomy, calmness, environmental stability, freedom from bias, human welfare, identity, informed consent, ownership and property, privacy, trust and universal usability. Issues such as 'not exploiting users' or 'providing due diligence when working with vulnerable users' are highlighted as key concerns. Most computing professional societies have codes of ethics (ACS, BCS, APA ACM/IEEE); for example, the ACM has its own (ACM 2013). Cairns and Thimbleby suggest that a "simple motivation for professional ethics is that it provides a generic framework to define 'best practice' that limits legal liability" (Cairns and Thimbleby 2003).

Previous research sought to discuss specific ethical concerns that HCI practitioners themselves located within their own work. A range of ethical dilemmas were surfaced, from the neglect of informed consent for fieldwork using video with internal participants (Mackay 1995), to preserving anonymity of participants in fieldwork when providing feedback to clients, through to delineating the limits of persuasion techniques in persuasive technologies. In the latter for example, Fogg et al (2003) assert that "ethical problems arise when the values, goals, and interests of the creators don't match with those of the people who use the technology". They provide a list of questions for HCI researchers to reflect upon to gain insight into potential ethical problems whilst also asserting 
that those who create or distribute persuasive technologies have a responsibility to examine the moral issues involved (Fogg 1998).

While HCI initially focused on cognitive and behavioural factors in the pursuit of universal usability, Knight (2006) notes that critics of this approach suggested that this reduced user experience to the lowest common denominator - focusing on ease of use ignored more sophisticated attributes of users. At the same time, HCI researchers began looking at other qualities such as, pleasure (Jordan 2000) and emotion (Norman 2003), with a focus on issues such as emotional associations, familiarity, aesthetics and taste. In his paper, Knight traces the deeper philosophical and moral implications of design in relation to these changes in focus.

With the advent and uptake of high-speed communication networks, the emphasis of HCI research shifted from a focus on the individual and their interactions with a computer, to that of the ways in which groups of people communicate with each other through computers (Grudin 1990). As technology became increasingly embedded in all areas and aspects of human life, the notion of human values and how these impact upon the design of computers emerged as a further significant area of HCI research (Friedman et al, 2006; Cockton 2006; Sellen et al 2009; Knobel and Bowker, 2011, Luger and Rodden 2013; Luger, Moran and Rodden 2013). Ethical areas of concern here typically include data ownership and protection, privacy, trust, system bias, autonomy, usability, informed consent, identity, green ICT, and professional ethics.

The notion and role of values, and especially social values in design has been widely debated in the literature. Borning and Muller (2012) provide an extensive review of the literature on values and ethics in HCI, highlighting the ambiguities that arise when designing from a cross- 
cultural perspective. For example, whose values will a system incorporate, what are the dangers to 'scientifically' determining what those values might be, and how can we be certain that these frameworks do not merely reflect the researchers' attitudes and sympathies?

More generally, the ubiquity, sophistication and power of current technological devices have transformed the ways in which accountability and knowledge are socially distributed, thereby effecting a change in the power relationships in society (Kobsa, 2009; Mort et al, 2003; Lanier, 2013). Sellen et al (2009) draw these perspectives into a broader picture locating the need for a values-aware approach within five contemporary techno-cultural trends: end of interface stability; the growth of technodependency; the growth of hyper-connectivity; the end of the ephemeral; and the growth of creative engagement.

The relatively recent emergence of social media systems and social computing has focused upon supporting "computations" that are carried out by groups of people, or between groups of people and machines as in collective adaptive systems (Anderson et al 2013), and once again the terrain becomes even more complex. New challenges now surface around familiar issues such as, privacy, informed consent, autonomy and identity. It is no longer a simple exercise to identify users or agency in this terrain or to give consent, and correspondingly, the job of professional ethics becomes that much harder as HCI researchers increasingly find themselves in unfamiliar territory (Bos et al 2009). To address this situation, recent work in HCI has sought to provide guidelines in particular areas such as trialing large-scale mobile software, where for example McMillan et al (2013) propose a set of ethical guidelines for large scale HCI user trials drawing upon professional principles developed in Psychology.

Responsible Research and Innovation 
As we will show in more detail below, there are limitations to the approaches to ethics in HCI. A key concern is whether research ethics concepts and practices inspired by bio-medical ethics are appropriate to HCI and whether they are compatible with other ethics traditions, notably those in the arts. We propose that a different perspective located at a higher level of abstraction is required, in order to find a way of harmonising conflicting ethical positions. We believe that the relatively recently concept of Responsible Research and Innovation (RRI) offers such a higher level perspective. RRI has recently emerged in Europe (von Schomberg 2013; Stilgoe et al 2013) and the US (Guston 2013). It builds on existing ethical frameworks and tries to overcome their limitations. RRI has be defined as 'doing science and innovation with society and for society, including the involvement of society 'very upstream' in the processes of research and innovation to align their outcomes with the values of society' (RRI tools project 2014).

Importantly for our argument RRI takes a broader perspective than existing ethical frameworks, changing the emphasis from philosophical reflection to practical governance considerations (Stahl et al. 2014). In their framework for RRI (Owen et al. 2013), adapted and adopted by the UK Engineering and Physical Science Research Council (http://www.epsrc.ac.uk/research/framework/) RRI is defined as seeking to:

- Anticipate - describing and analysing the impacts, intended or otherwise, (for example economic, social, environmental) that might arise. This does not seek to predict but rather to support an exploration of possible impacts and implications that may otherwise remain uncovered and little discussed. 
- $\quad$ Reflect - reflecting on the purposes of, motivations for and potential implications of the research, and the associated uncertainties, areas of ignorance, assumptions, framings, questions, dilemmas and social transformations these may bring.

- $\quad$ Engage - opening up such visions, impacts and questioning to broader deliberation, dialogue, engagement and debate in an inclusive way.

- $\quad$ Act - using these processes to influence the direction and trajectory of the research and innovation $(\mathrm{R} \& \mathrm{I})$ process itself.

In addition to reflecting on possible impacts and purposes of R\&I, the framework thus underlines the necessity to anticipate impacts of R\&I and engage with relevant stakeholders to discuss them further. Moreover, to ensure their practical use, reflection, anticipation and engagement are aimed at informing the governance of R\&I processes. Including the four dimensions of the framework into R\&I then allows researchers and innovators to ensure societal and ethical acceptability of their work.

RRI has been discussed in relation to a widening range of fields of R\&I, for instance, in information systems (Stahl 2012), ICT (Stahl, Eden, and Jirotka 2013), nanotechnology (Simakova and Coenen 2013), finance (Muniesa and Lenglet 2013), and synthetic biology (Mason 2012). Also, in current research within HCI, RRI is considered in relation to the practices of responsible design and innovation (Grimpe et al 2014).

In addition to the general societal and political demand, currently voiced by the EU and national governments (NWO 2010; EPSRC 2014), to consider the wider impacts of R\&I (European Commission 2011), HCI's turn to the cultural, as highlighted in this paper, further warrants 
attention by RRI. The cultural turn represents a further widening of HCI's interests and concerns challenging the existing ethical thought within the field. New ethical issues and challenges arise, not only by including art as an object of HCI, for example digital art, but also by deriving new methods from art to HCI, for example through the use of uncomfortable interactions.

In this paper RRI is explored as a way to address the challenges arising from HCI's turn to the cultural. It examines the operationalisation of the framework of RRI within the context of case studies on art projects that involved collaboration with HCI researchers and artists. For this purpose a workshop was staged:

- involving 40 artists, performers, curators, art commissioners and funders (Engage),

- to discuss possible ethical and social challenges of arts-driven research within HCI (Anticipate / Reflect)

- $\quad$ and how we might deal with these challenges $($ Act $)$.

By discussing the findings of the workshop we try to surface new ethical challenges that HCI needs to consider in its continuing engagement with the cultural; to populate these with a set of examples; and ultimately to explore RRI as a novel approach to handling ethics in future projects. We thus position the paper as a practical exercise in RRI. In order to demonstrate why such an application of RRI is necessary, we now discuss competing ethical perspectives arising in the tradition of performing arts.

\section{Ethics and performance}

The term ethics can be traced back to the Greek ethos or character, which presupposes that ethics can be described as 'the study of character' (Ridout 2009: 9]) or the idea of 'acting in character' (Ibid: 10) which then 
presumes that there is a possibility that one would know how to act (Ibid.: 12) or that there is a right, or ethical, way to act. Implicit in this, as Nicholas Ridout points out in his study Theatre and Ethics is also the idea that theatre tends to dramatise ethical situations (Ibid.: 13) by inserting 'its ethical questions into the lives of its spectators' so that these become 'unusually conscious of their own status as spectators, and thus of people who may exercise ethical judgment' (Ibid: 15). So, for Ridout, it is significant in the theatre that "we watch ourselves watching people engaging with an ethical problem while knowing that we are being watched in our watching (by other spectators and also by those we watch' (Ibid.: 15). Historically, different forms of theatre have variously engaged with ethics, though generally we can say that the issue of ethics has always had to do with the act of witnessing an event. Thus, ethics has always been a paradigm in shaping actors' and performers' engagement with their audiences, and viceversa.

In naturalist and realist theatre forms, audience members have conventionally been confined to the role of 'voyeurs', the theatrical event being held behind an imaginary 'fourth wall'. However, this traditional view has been challenged from the 1930s onwards by the emergence of Brechtian practice which, through the introduction of the distancing effect (Verfremdung), aims to confront the audience with different points of view, hence putting the spectator into the position of having to make a decision about what they are seeing. In other words, the audience is implicated in the ethics of what they view by being there, and their implication affects this act of viewing, creating agency for the viewer. Thus for Brecht, a defamiliarisation needs to be introduced: 'alienations are only designed to free socially-conditioned phenomena from that stamp of familiarity which protects them against our grasp today' (Brecht in 
Willett 1993: 192). This defamiliarisation intends to place the viewer into an ethically and politically conscious position.

In the aftermath of the Second World War, the problematics of witnessing an act of suffering started to be addressed as a matter of priority. Viewing traumatized bodies was described as an 'eroticization of atrocity' (Jacobs 2008): it was felt that audiences should respond to viewing atrocities by not just passively witnessing the atrocity, 'turning away' and 'pretending not to see', which would put them in a position of 'unethical spectatorship' (Oliver 2010: 121), or, equally, 'looking on' (French 2002 and Jacobs 2008), but rather that audiences should find a way to be 'response-able' (Oliver 2001).

In Brechtian practice the audience is positioned outside the work, though through defamiliarisation, the mechanism of theatre is disclosed to them, but in performance art and new media work developed since the 1960s, the audience is often positioned inside the work and the frame separating the performance event from life itself is left deliberately opaque, challenging the audience's ability to tell art apart from life. This, in turn, problematises the audience's position as an 'ethical' witness for spectators are no longer able, as in Brechtian practice, to tell what is being witnessed apart from their own act of viewing. This aesthetic strategy was characteristic of early happenings, performance art and body art. Examples abound, such as Vito Acconci's Seedbed (1972) in which the artist lay beneath a ramp in the Sonnabend Gallery masturbating while his fantasies about the visitors walking above him were heard through loudspeakers; Chris Burden's Shoot (1971) where the artist was shot in his left arm by his assistant from a distance of five meters with a .22 rifle and Trans-fixed (1974) where he was nailed to the back of his Volkswagen; or Orlan's 
Omnipresence (1994) in which the artist theatricalized and broadcasted her cosmetic surgery.

Bauman (2008) discusses the notion of culture as a 'declaration of intent', involving two opposing views of culture - where culture is 'managed' through actions either by those who are doing the acting or those that are 'bearing the impact of the action', or that where culture is framed in opposition to the status quo and allowing a voice to those that are powerless. Within the ethical space encompassed by these opposing views of culture emerges the important role dialectics in how artists become creators of culture. Bauman argues that artists and managers (institutions, administrators and the upholders of the status quo) need each other in order to bridge art and society, yet this work questions how we contract out responsibility to others. Bauman argues that by applying different forms of measuring our consumption of culture, such as institutional and governmental led processes, the artists' dialectic can be lost and silenced by society's desire for quick and simplistic solutions without questioning the meaning of 'being in charge'.

Within performative practice these questions of intention, who is in charge and what it means to be in charge are interrogated through the very dialetics that Bauman argues can be silenced by forms of measurement and processes of defining responsibility. Goodall describes how work, such as the artists Orlan and Stelarc, offers a dialectic that functions as a political and ethical device and enables us to 'rethink what it means to be an agent, how the legal, moral and ethical liabilities can be encoded' (Goodall, 2005).

The emergence of interactive and new media arts, including especially biomedia and bioart, has further problematized the issue of ethical viewing or participation to performance, as the examples of Stelarc's Ear on Arm 
(2008), Symbiotica's recurrent use of semi-living skin in their artwork, and Eduardo Kac's creation of a transgenic rabbit in GFP Bunny (2000) show. The advent of computer and pervasive games as a new and vibrant cultural form also inspired interactive performance works in which audience members become active participants, explicitly responsible for acting in a 'mixed reality' both within and outside of the fictional frame created. The spread of this interactivity to online and social media has potentially extended such interactions to include and directly affect other participants, so that participants may be morally accountable for how their actions within the performance affect others (actors, audience members and passers-by). Indeed, much has been written in theatre and performance studies about the philosopher Emmanuel Lévinas's suggestion that the subject constitutes itself by taking responsibility for the other (1985), a concern that is particularly powerful in the context of interactive and pervasive media games and performances in which passers-bye often have no way of telling they are witnessing an artistic event.

The advent of mobile media has contributed to the blurring of digital, fictional and physical spaces as well as a blurring between the content developer, the participant and the audience or consumer of the content. Writings in HCI have articulated how locative-experience may ambiguously blur the 'performance frame', implying that real world settings, events and even passersby are somehow part of the theatrical experience and establishing complex relationships between performances, audience and bystanders who may also become implicated in events (Benford et al 2006; Sheridan et al 2007). Finally, these participants are increasingly invited to contribute their own materials and performances, essentially becoming authors of the work as well as participants in it. In the case of some alternate reality games as we discuss below, participants 
may even begin to take control of the underlying 'rules' that determine the form and boundaries of the performance itself. Scholarship developed in this context has drawn attention to the power game-masters hold over participating audiences which can be 'very asymmetric and nontransparent' (Montola et al 2006: 2).

There has been a trajectory in performance from passive spectating with an associated set of practices, norms and values mostly expressing social and psychological distance, to active engagement and even enrolment, with a consequent shift in practices, norms and values that reflect a lessening of this distance. As a result of this trajectory, the theme of ethics has become increasingly significant, and dedicated conferences and work groups, such as the creation of a journal on theatre, performance and ethics in 2008; the 'Delegated Performance' conference at Stanford University (Palo Alto, 2011), where art historian Clare Bishop looked into the ethics of delegated performance where artists delegate audiences to perform; the Garage's 'First International Conference | Performance Art: Ethics in Action' (Moscow 2013) discussing the ethics of political performance in Russia, focusing on the work of artists like Pussy Riot and Pyotr Pavelensky who in 2013 nailed his scrotum to Red Square in protest against rules against homosexuality.

\section{Exploring the ethics of HCl's engagement with the performing arts}

Drawing these three threads together, we suggest that HCI's growing engagement with the performing arts takes us into rich and complex ethical territory. On the one hand, $\mathrm{HCI}$ is engaging with a discipline that is far removed from the traditional settings of human-subjects research, whose values might be less familiar, and that is apt to confront the ethical status quo. This is already raising challenging ideas - for example the 
deliberate use of discomfort in interaction design - and looks set to continue doing so in the future. On the other hand, the performing arts are themselves turning to emerging forms of interaction that have been studied within HCI, albeit in other contexts, and where there is an established body of design knowledge, including discussions of values and ethics. It is important to consider what happens as these value systems collide. This becomes particularly important when we consider the third thread, the increasing pressure to comply with institutional research ethics, which demands that researchers (and practitioners too) are able to cogently explain and justify their activities.

\section{THE 'ACT OTHERWISE' WORKSHOP}

Having reviewed relevant previous work on ethics within both HCI and the performing arts, we now describe how we set about exploring the ethical issues that arise when these fields come together. As described above, our approach to this challenge was shaped by the approach of Responsible Research Innovation. We sought to engage actively with ethical tensions and moral dilemmas as they had arisen throughout the course of previous projects through a process of deep ethical reflection and debate.

We therefore convened a three-day workshop called Act Otherwise in February 2013 to bring together practitioners and researchers to debate “the conflicts that often arise between artists' work and ethical approval, the ethics of working in a public space and the ethics of interactive work" (Blast Theory 2013). The aim was to create a unique forum in which practitioners, researchers and curators could share their experiences, uncover ethical challenges, compare their approaches, and consider ways of sharing best practice. The workshop was attended by thirty-eight participants, including representatives from fourteen different artists 
(groups and individuals); researchers with interests spanning HCI, arts and humanities, and the ethics of e-Research; curators and commissioners; and business development staff from artists groups and research institutions.

Day one revolved around a series of presentations that introduced and discussed four pre-selected case studies, providing us with concrete and detailed examples of projects that we believed a priori raised ethical issues from both performance and HCI perspectives. These four case studies were complemented by two further presentations that aimed to frame initial ethical issues from a research point of view, one presenting the idea of deliberately making users uncomfortable in order to entertain, enlighten or socially bond them, and the second providing an overview of the ethics of conducting e-Research.

Day two involved two rounds of subgroup discussions (with plenary feedback) to surface and then unpack ethical challenges. The first round split into four groups, each focused on interrogating one of our four selected case studies in greater detail. The second round focused on how we might ultimately communicate ethical thinking to four different constituencies: practising artists; academic researchers and their institutions; curators and commissioners; and public audiences. At the end of the day, participants were invited to contribute topics for further discussion on a shared notice board which the organisers then grouped into the overarching themes of: negotiating boundaries, consent, artistic versus scientific integrity; the process of making artistic work and ethics; and what the outputs of the workshop should be.

Day three involved a series of discussions around these emerging themes, but also deliberately introduced some new examples into the mix at key points so as to refresh the debate. These included a UK national television pilot that had explored the challenges of staging an interactive 
text messaging game for teenagers to explore personal relationships and issues concerning sex and drugs, and a further alternative reality experience that used layers of conspiracy to blur the boundaries between fiction and reality.

The workshop was initially written up as a series of field notes that fed into a further smaller workshop among the authors of this paper several months later at which the findings were discussed and refined, and from which a further set of themes and issues emerged.

The following sections now present the results of this process. We begin by summarizing our four pre-selected case studies before then discussing our final ethical themes (illustrating them with the case studies and through other examples that were raised at the workshop).

\section{CASE STUDIES}

Our case studies focus on four different artists who produce public performances across quite diverse areas of the performing arts, and who have also all been involved in collaborations with HCI researchers. The work of all four has previously featured in the HCI literature and so the following provides just a brief review of their practice and a few key examples of projects that are necessary illustrate subsequent discussions.

\section{Blast Theory}

Blast Theory are a UK theatre group who use interactive media to create groundbreaking new forms of performance and interactive art that mixes audiences across the internet, live performance and digital broadcasting. Their body of work dates back to 1991, with early examples featuring challenging technology mediated performances such as Kidnap (1998) in which two winners of an online competition were kidnapped and held for forty-eight hours, with the process being watched by online viewers who 
were able to follow and comment on events over the Internet, including making suggestions as to what should happen to them.

Desert Rain (1999) was an exploration of the first gulf war and its relationships to computer games, film and journalism in which six players at a time were sent on a mission into a game-like virtual world that was embedded into a wider physical set through the use of six 'rain curtains', projection screens composed of a fine water spray through which players and also actors could pass. Studies of Desert Rain revealed how Blast Theory, through military style briefings and subtle interventions in the virtual world, carefully orchestrated the experience to ensure that participants were vulnerable and disoriented and to create situations in which the group had to decide whether to leave one player behind in order to complete their 'mission' (Koleva et al, 2001).

Uncle Roy All Around You (2003) was one of a series of performances that took place on a combination of the city streets and online virtual worlds that appeared to be connected in various ways and where 'street players' could engage with 'online players' (Benford et al 2006). Street players explored the city in search of Uncle Roy, following a series of ambiguous clues that got them lost and disorientated, invited them to follow a stranger at one point, and ultimately led them to explore a deserted office and then climb into a limousine where they were interviewed by an actor. Online players were able to follow their progress and send them messages to help them on their way or further confuse them if they wished. 

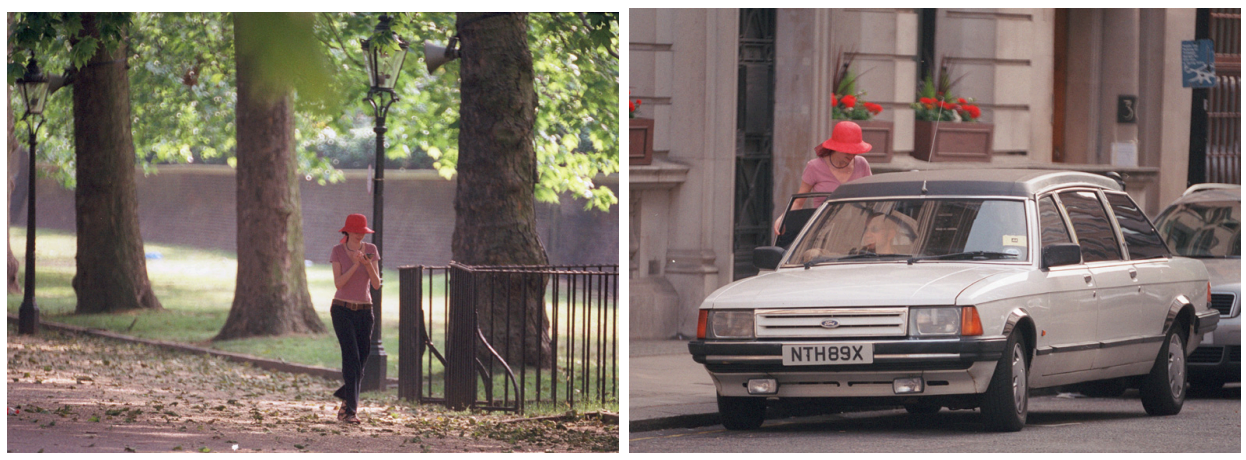

Figure 1. Blast Theory's Uncle Roy All Around You. Following clues through the city (left) and entering the limousine (right).

Ulrike and Eamon Compliant (2009) addressed the theme of terrorism. Participants undertook a guided city walk as they listened to excerpts from the life of one of two notorious terrorists, Ulrike Meinhoff of the Red Army Faction or Eammon Collins of the IRA (Tolmie et al, 2012). The experience demanded increasing compliance with instructions, including making public gestures, suggesting that participants are under surveillance, and culminated with a one-on-one interrogation by an actor who questioned them about obligations to act on political beliefs and the consequences of taking such actions.

Ivy4Evr (2010) was an interactive text messaging drama for teenagers, commissioned by the UK's Channel4 Television as an educational experience to explore issues of sex, pregnancy and drugs (http://www.blasttheory.co.uk/projects/ivy4evr/). Over seven days, audience members exchanged text messages with Ivy (an automated bot) whose narrative revealed intimate details of her life and the dilemmas she faced. Over time, the messages became more personal and intimate, with each participant able to decide how far the conversation progressed. 

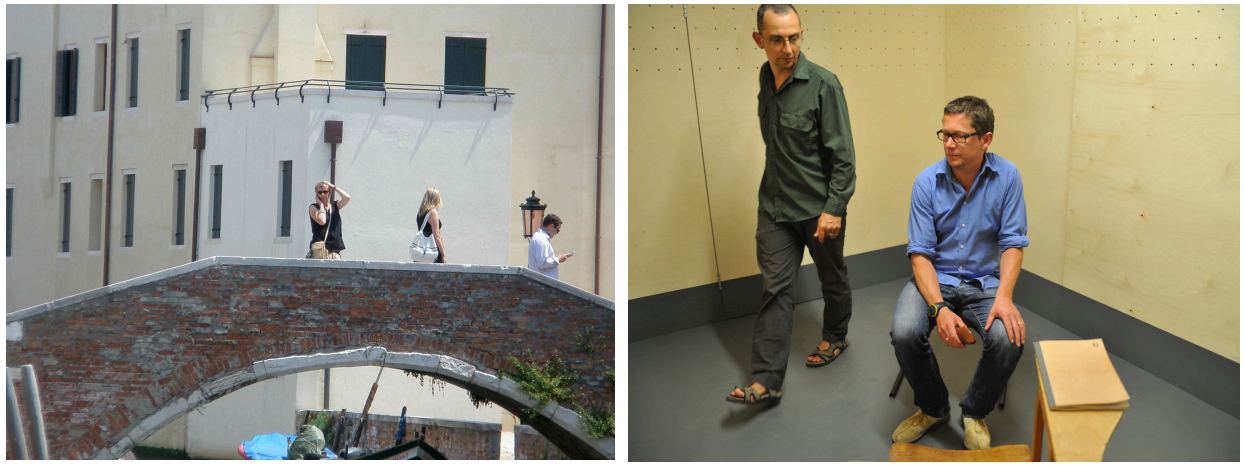

Figure 2. Blast Theory's Ulrike and Eamon Compliant. Showing compliance with instructions (left) and the final interrogation (right).

\section{Brendan Walker}

Brendan Walker is an artist, designer and television presenter who has been working in the context of the mainstream entertainment industry, including in both amusement parks and television, since 1997. Brendan's work focuses on delivering tailored emotional experiences with a particular emphasis on designing thrilling interactions and also on revealing these to spectators and ultimately, back to participants themselves. Three projects are of particular interest here.

Thrill Laboratory (2007- ) encompassed a series of projects to capture and broadcast riders' physiological responses to rollercoasters. The first performance took place at the London Science Museum and involved capturing live video, audio, acceleration and also physiological 'biodata' heart rate and galvanic skin response (sweat levels) - from competition winners who got to experience three different rides at a performance event (Schnadelbach et al, 2008). Subsequent performances took place at Alton Towers, a major UK theme park, in which riders were shown their own data as part of a debriefing after the ride. From there, the technology found its way into more commercial use, first being used to create a series of television articles for the Discovery Channel and the BBC in which 
presenters tried out various rides, and subsequently being used to create a series of promotional films for thrilling experiences including a trailer for the Hollywood movie Sinister that revealed viewers' reactions to watching the movie and the 'Built to Thrill' advertising campaign for the Nissan Juke car commissioned by the company TBWA that captured biodata from competition winners taking part in a series of thrilling experiences (Reeves at al 2013).
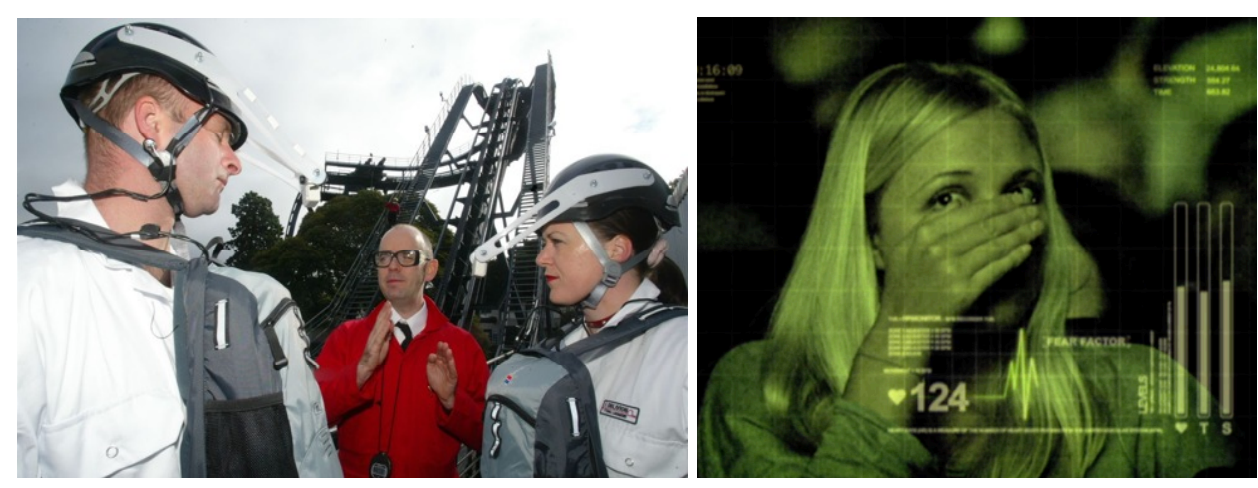

Figure 3. Brendan Walker's Thrill Laboratory. Capturing biodata from riders on Oblivion (left) and from viewers of Sinister (right).

A series of prototype amusement rides explored how this kind of physiological biodata might actually be used to control an interactive ride. A first performance that explored how a human operator might control a bucking bronco ride based on seeing video and biodata from a rider, inspired the design of the Broncomatic (2010), a breath-controlled version in which the rider's breathing (sensed through a chest strap monitor) caused the ride to buck, setting up an unstable human-in-the-loop control dynamic (Marshall et al, 2011). Breath sensors were subsequently embedded into a rubberized gasmasks that were worn by the riders of Breathless (2011), a breath-powered swing ride. Breathless also established an unusual performance dynamic in which a participant would first watch another as a 'voyeur', then rode the swing, and finally take on 
the role of the controller, taking control of another rider's experience half way through (Benford et al, 2012).
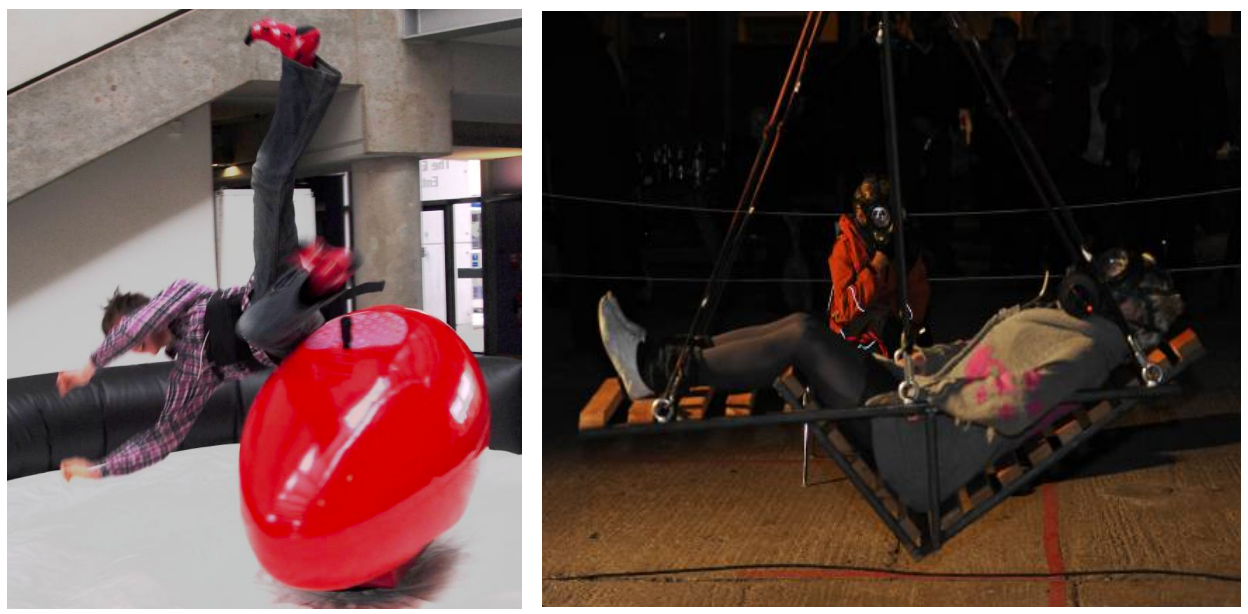

Figure 4. Brendan Walker's Broncomatic (left) and Breathless (right)

Our final example of Brendan's work is a commercial experience that was developed for Thorpe Park, a major amusement park in the UK, in which participants donned gas masks that were instrumented with video cameras and respiration sensors, and were sent into the Saw Alive horror maze, while spectators, typically family members, remained outside to share their experience vicariously from a distance.

\section{Active Ingredient}

Founded in 1996, Active Ingredient is an artist-led collective that creates artwork and conducts research into the blurred boundaries between technology, art and science. Of particular relevance to this paper is their work A Conversation Between Trees (2010), an artistic exploration of environmental sensing and climate data. This comprised a mixture of performance and installations that juxtaposed contrasting experiences of scientific data. 

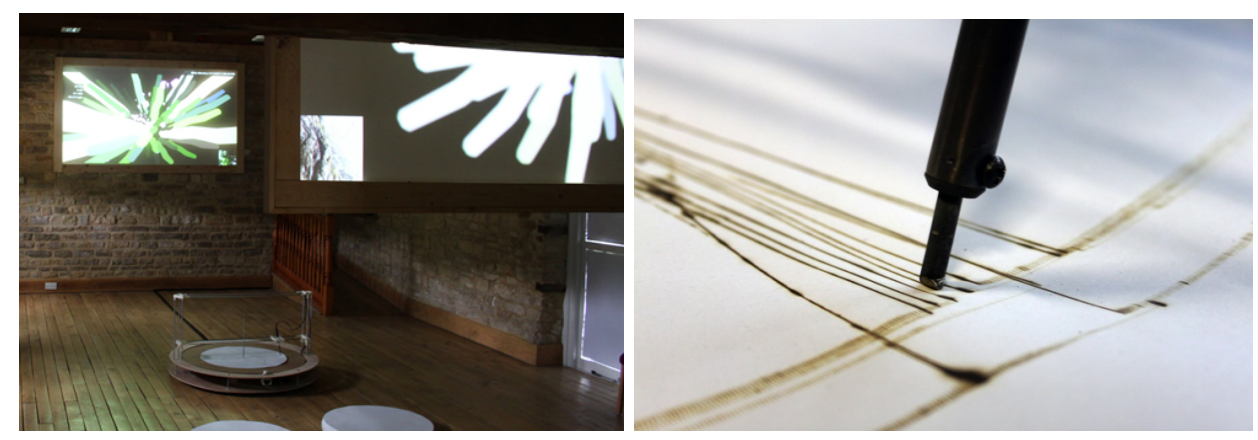

Figure 5. Active Ingredient's A Conversation Between Trees. Visualising environmental data from two trees (left) and burning climate data (right) At the core of each experience were two trees, one located in the Mata Atlantica forest close to Rio de Janeiro and a second chosen to be close to the current hosting venue (typically in a forest in the UK). Each tree was instrumented with a sensor kit that measured local temperature, humidity, noise and carbon dioxide levels once a minute and transmitted these back to the host venue where they were visualized on two large screens that faced each other across a gallery space. Between these was located the 'climate machine', a distinctive looking artefact that slowly burned climate data onto circular disks of paper that there were then hung up in the gallery as if they were slices through the trunk of a tree. On the advice of a climate scientist, Active Ingredient chose to work with the Mauna Loa dataset, a lengthy series of monthly average $\mathrm{CO} 2$ readings recorded at the Mauna Loa observatory in Hawaii dating back to 1959. Finally, visitors could collect a smartphone and take it out into the local forest to act out the role of being a sensor. The phone captured images every second which were visualized in a similar way to the sensor data in the gallery, while participants were periodically invited to reflect on the feeling of being in the forest. A study of A Conversation Between Trees as it toured through three different venues revealed how the artists sought to establish an emotional rather than a didactic engagement with scientific data and how 
they used various performative strategies to achieve this, including liveness, slowness, materiality and embodiment (Jacobs et al, 2013).

\section{Urban Angel}

Our final group, Urban Angel, are a voluntary arts organization working predominately with performance and making extensive use of digital technologies. Of particular relevance here is their recent project The Malthusian Paradox (2012), an alternate reality game (ARG) that involves players in an apparent scientific conspiracy surrounding genetically modified crops, a fictional company called TFT and an equally fictional and mysterious activist organization called AMBER who are campaigning against TFT (Evans et al, 2013). ARGs typically deliver a game or narrative to players over multiple media and also engage them in visiting physical locations and solving puzzles. They often consciously set out to blur the boundary between fiction and reality, sometimes even claiming that they are not games, although their framing typically reveals that they are (McGonigal, 2011).

The Malthusian Paradox involved a community of 300 participants in total. The game began with a public lecture by Dr Solomon Baxter (repeated in four different towns) who purported to be a world-renowned environmental scientist who was to speak on a new discovery. Partway through, three men wielding guns burst in, threatened the audience to remain seated, and wrestled Dr Baxter to the floor before bundling him out of the theatre. Shortly afterwards Dr Baxter's daughter Rachel arrived with Alex, a representative of AMBER, and they implored the audience to join the organization to help uncover the truth behind Dr Baxter's discovery and to help locate him. At this point audience members were invited to sign up as players, although this is also subsequently possible via the game's website. 
Each fortnight a new episode of the game was released comprising a short film along with clues that pointed players to particular puzzles or activities. There were six episodes in total, with typical activities including: visiting various venues to meet Rachel and Alex, visiting websites, making phone calls and sending text messages. Key moments in the game included players witnessing live graffiti, being invited to stage a public protest in a city centre, reassembling shredded paper documents, locating and unlocking a physical safe, and hacking the TFT website. In a key dramatic moment, some players were kidnapped in public and driven to an office where they were interrogated as to what they knew of the story thus far. The game ended with Dr Baxter being killed and Rachel being revealed as a double agent.
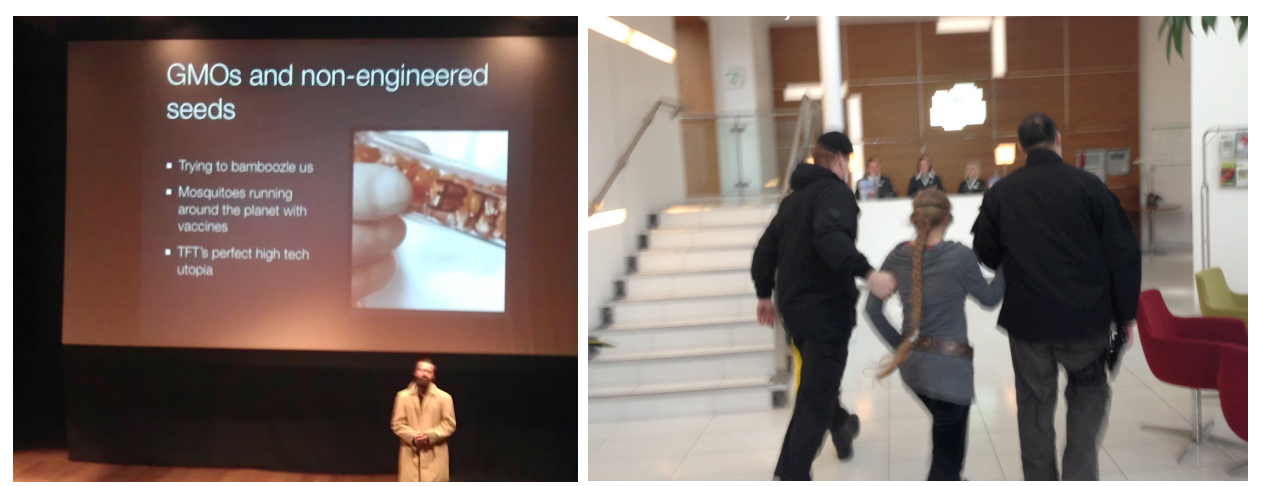

Figure 6. Urban Angel's The Malthusian Paradox. Dr Soloman Baxter's lecture (left) and kidnapping a player (right).

\section{REFLECTION ON ETHICAL CHALLENGES}

Following the RRI approach, we now 'reflect' on the discussions of our case studies, and also on further examples introduced by participants, at the Act Otherwise workshop in order to reveal key ethical challenges. These are grouped under the six overarching themes of: transgression; boundaries; consent; withdrawal; data; and integrity.

Transgression 
The artists, performers, curators and commissioners who were present were clear that many ethical challenges stemmed from the inherently transgressive nature of artists and their artworks. As noted in our earlier literature review, there is a long history of artists challenging the established moral order of the day and of pushing the limits of what is deemed to be publicly acceptable. Workshop participants referred to the artist as a 'trickster' or 'fool' who is in a position to say what others may not, poke fun at the establishment and criticize the status quo.

Such challenges may be overtly political and directly visible in the theme of the work, for example Blast Theory's treatment of the First Gulf War in Desert Rain, of post 9/11 surveillance culture in Uncle Roy All Around You, and of terrorism in Ulrike and Eamon Compliant. This observation mirrors previous discussions in HCI of ecologically-engaged artworks that adopt an overtly activist stance towards the topic of sustainability (DiSalvo 2009). However, less overtly activist approaches are also evident, for example Active Ingredient's $A$ Conversation Between Trees strives for a more emotional and gently questioning engagement with the politically charged territory of climate and environmental data. Whatever the approach, it is important to recognize from the outset that artworks often confront the social, political and moral order of the day and so may frequently seek out and foreground contemporary ethical challenges.

Transgression is also to be found in the structure of performances as well as in their theme. As noted earlier, interactive performance repositions audience members from being spectators of events to being participants and sometimes even performers and co-authors within them. While spectating already introduces ethical questions - should I passively witness these events? - interactivity implies further moral agency through 
directly making decisions that have outcomes, both for the participant and often for others too. Examples abound, from the earliest Blast Theory works onwards: Kidnap invited online participants to collude in the fate of the kidnappees, Desert Rain created situations in which teams members had to decide whether to leave an individual behind in order to progress, while Uncle Roy All Around You gave online players agency over street players by sending them messages and directions.

The mobile and pervasive nature of many of the works considered here, where interactive content is embedded into physical settings such as theme parks, woodland and frequently, the city streets, introduces further possibilities for transgression. Many of these works take place in what would be considered to be 'normal public' settings (rather than behind closed doors and so naturally involve bystanders, that is passersby who may become unwittingly implicated or even involved in the work (Sheridan et al, 2007). Moreover, these bystanders may bring along their 'normal' expectations as to how things will go to these settings, raising ethical questions when these are willfully breached and further questions concerning their involuntary sense of involvement and implication.

As just one of many possible examples, The Malthusian Paradox encouraged participants to take part in street protests and staged a kidnapping in front of bystanders. Finally, the online 'space' of the Internet can also be considered to be a public environment in which participants' actions may be made visible to bystanders.

Many of these works encourage people to transgress personal boundaries, testing personal limits. This is perhaps most obviously evident in Brendan Walker's 'thrill' projects which, like amusement rides in general, encourage people to confront fear by deliberately choosing to subject themselves to an intense and potentially uncomfortable experience. 
The nature of works such as Thrill Laboratory and Saw Alive, in which close-up views of these experiences were then broadcast to others, including loved ones, introduces further transgressions and ethical dilemmas as we discuss later on. Even when not directly 'fearful', works such as Ulrike and Eamon Compliant engage people with material that they might find distasteful (accounts of acts of terrorism for example) and moreover may do so in a way that appears to suggest complicity or at least acceptance.

In short, the kinds of interactive and pervasive performances that we describe here can be inherently transgressive in a variety of ways. This gives rise to various other ethical challenges as we now discuss.

\section{Boundaries}

A key challenge lies in judging participant's personal boundaries, specifically how far to push the experience. For interactive performances, and especially for those that involve live actors or orchestration, this is often a matter of fine judgement by performers, made on an ongoing basis as they observe and interact with their audiences. A good illustration is provided by the first Thrill Laboratory experiment from 2008 in which video, audio, heart-rate and acceleration data were captured and broadcast from the riders on amusement rides, including one quite extreme ride called the Booster. In one case, reported in Schnadelbach et al (2008), one of the riders used the live audio link to request that the ride be stopped. This occurred at the point in the ride when the riders have been raised up to a maxim height above the ground just before the main ride began, which is potentially a peak moment in the intensity of fearful anticipation. It transpired that this rider was actually pleading on behalf of the person sitting next to her (rather than for herself) who was, in her view, extremely scared. In this case, the ride operators decided to continue with the ride as 
normal. A parallel example was thrown up by the Saw Alive experiment in which a mother entered a horror maze wearing similar broadcast technology and where her daughter, who was watching her over the live link, requested that the experience be terminated because she felt her mother to be too scared. Again, the decision was to continue with the experience, which the mother ultimately reported having enjoyed, although evidently the daughter did not.

These examples of people confronting fearful experiences help illustrate some important facets of judging boundaries. First, it can be a difficult matter of professional judgement and experience to decide how terrified or deeply disturbed a participant may be, and consequently how far out of their comfort zone - or even beyond control - they may be. Second, one needs to weigh the consequences of stopping the experience against that of carrying on. For example, winding the Booster back down to ground level and getting the person off may take longer, and ultimately be more humiliating, than carrying on. Then there is the matter of the timescale, which requires guessing how the participant may feel later on compared to how they feel right now. Finally, the difficulty of judging a personal boundary may be further compounded by the presence of others, for example, loved ones who are vicariously fearful on their behalf. Not only may they have strong views, but there is also the question of how to manage their own personal boundary as a spectator.

This raises an important question: who has the right to make such judgments and what is their responsibility for the judgements they make? How are the different senses of having the right (the person next to the 'freaked out' rider, the daughter, the operator of the ride) to be calibrated? The question of who knows best - the seasoned performer (or perhaps ride operator) or the friend or family member - is a difficult one to which there 
are no off-the-shelf answers. The professional may be able to draw on extensive experience and a degree of detachment when judging boundaries, however those familiar with the participant may know them well, though perhaps not in this situation, but may be strongly influenced by their own feelings. Of course, managing spectators' experience now becomes part of the judgement that needs to be exercised by professionals as the technology serves to draw inside the action.

Judging personal boundaries becomes more difficult still when participants are invited to overtly play roles rather than be themselves, as now one must judge whether they are acting in character or are genuinely heading into difficulties. As we shall describe below, experiences such as The Malthusian Paradox and Blast Theory's Ivy4Evr involved fine judgements about what participants were actually experiencing based upon what they were saying in role-play situation.

Inspired by these examples, our workshop participants raised many similar examples of having to judge limits when pushing personal boundaries. While the fine detail varied, they were in broad agreement that this needed to be an ongoing matter throughout an experience and that it relies on establishing and maintaining an ongoing relationship of trust with participants, rather than being able to formally agree boundaries and limits in advance - an issue we return to when discussing consent below.

Further boundary negotiations arise from the public nature of many of these experiences - that they take place in spaces that are shared with others, many of whom may be unwitting bystanders who are unaware of the nature of the artwork, or perhaps even that an artwork is unfolding. First, there are potential risks to the participants themselves. The work might encourage them to behave inappropriately or even illegally. Uncle Roy All Around You invited participants to enter an office that had been 
rented for the occasion, but in so doing raised the possibility that they might try enter some other office. The second performance of Uncle Roy All around You took place in an area of a city that appeared to be frequented by drug dealers who appeared to be suspicious of the performers' presence. In response, Blast Theory changed the route that participants follow through the city to steer them away from this area.

Then there are potential risks to bystanders who might be affected by the experience. For example, in staging their public kidnapping, Urban Angel were mindful of the bystanders who would witness the event. Their approach in this particular case was to monitor the space carefully so as to avoid staging an apparently traumatic kidnapping in front of children. Bystanders might also be caught up in the action (taxi drivers were asked for directions to Uncle Roy's office) or might at least be inconvenienced by it, especially if an unexpectedly large number of participants turn up to take part. In practical terms, there may be a need to notify the relevant public authorities as happened for some of the key public events for The Malthusian Paradox such as the street protest.

The final boundary to be negotiated concerns the rules of the experience - ultimately what is acceptable within the frame of the experience. For many of the experiences we have considered, the rules are tightly scripted in advance, even if more ambiguously presented to participants. Uncle Roy All Around You is highly scripted and constrained, even though aspects of it such as the relationship to bystanders are presented in an ambiguous way. This approach is typical of many of the experiences discussed at the workshop in which participants are offered an illusion of choice. While participants in Uncle Roy All Around You may feel like they can go anywhere in the city, the combination of clues and live orchestration inexorably steer them to Uncle Roy's office within an allotted time. 
Indeed, offering the illusion of choice against the backdrop of a carefully scripted and managed experience is one way of pushing boundaries but within tightly defined limits. However, not all experiences operate in this way. The Malthusian Paradox, for example, saw examples of groups of participants taking charge of the rules and deciding to stage their own events to which the artists then had to respond. In this case, the underlying rules of the experience - perhaps the very last boundary - were opened up for negotiation.

\section{Consent}

The principle of informed consent, which covers both what is done and the information that is gathered, is a cornerstone of medical and experimental ethics. It is therefore also central to practical considerations of research ethics within HCI. In brief, the principle argues that participants, traditionally in research experiments or medical interventions, should formally agree to take part in advance and that this agreement should be on the basis of having been properly appraised of the nature of the 'procedure' along with any consequences that may follow and risks involved. As noted earlier, some sociologists have already argued that the conventional interpretation of informed consent may be too heavyweight for social science research where the risks are lower, issues of concern will emerge throughout the study rather than being known in advance, and trust between research and participants is 'earned incrementally' (Kent, Williamson, Goodenough, \& Ashcroft, 2002; Pattullo, 1982; Whittaker, 2005). A key issue for (qualitative) sociologists lies not so much in getting consent to enter the field to 'hang around' and collect data, but with asking people to consent in advance to the gathering of specific forms of information when they don't know what they will collect. 
Our discussion of negotiating boundaries suggests that there may be similar concerns for culturally-oriented research projects that involve creating and studying public artworks and performances.

The first essential difference is that audience members come to a performance as consumers who have agreed to 'buy' a product rather than participants in a research experiment. While there is often a point of formal agreement with the audience, typically the point at which a ticket is acquired in order to gain admission, this is relatively lightweight compared to fully-fledged informed consent. Tickets can represent some aspects of a formal agreement between audience and venue/artists in terms of date and time of performance, right to a seat and possibly agreement to age restrictions. However, they say relatively little about the nature of the experience. More background may be gleaned from marketing materials, reviews, ratings systems and from the general reputation of the venue, all of which can help to set expectations. In spite of this, however, the detailed nature of the experience may remain largely unknown, and indeed, quite often be deliberately withheld. This relies on a high degree of trust between audience, artist, venue and commissioner/curator. It also devolves considerable responsibility to the participants themselves for making their own judgement as to appropriateness, for example parents judging whether experiences are appropriate for their children. The ethical challenge lies in judging what it is reasonable for an audience to expect given the available knowledge of the artist, venue and so forth and whether any additional warning should be provided. Beyond this, consent may then be negotiated during the experience on an ongoing basis as it unfolds, gradually building trust. Thus, it may be unreasonable to require fully informed consent in advance of taking part in a cultural experience. Moreover, to do so might undermine the point of many of the experiences, which are supposed to 
shock or breakdown traditional hierarchies where the audience is passive and 'being done to' by the performer or artist.

This said, the works described above served as research studies as well as cultural products. Our goals as researchers were both to develop innovative and worthwhile cultural experiences, but then also to study them in order to unpick how they were experienced and made to work with a view to revealing new principles for HCI. It could be argued that the study aspects of cultural experiences should require a more conventional form of informed consent that addresses how data will be gathered, stored, analysed and reported, even if it does not set out the nature of the experience itself in detail and, indeed, this has typically been the case for the experiences reported here. However, it may be difficult for people to consent to having data collected from an unknown experience, after all how can they gauge how they might react and whether they are happy to have this recorded and subsequently analysed? This suggests that it is important to revisit consent after the event and/or to allow inspection or curation of captured data as part of the process. This line of argument mirrors recent discussions in HCI around the nature of consent in relation to ubiquitous computing in general, where researchers have argued that consent should be negotiated through an ongoing process rather than at a single moment (Luger, Moran and Rodden, 2013).

There are other challenges around consent too. Experience shows that some artists may be wary of researchers engaging audiences with official forms at the start of experience as this may introduce an inappropriate framing, for example where the critical first contact with the performance becomes a researcher wielding a consent form. Notably, our experience with The Malthusian Paradox involved the reverse problem. The framing of the work around a scientific conspiracy led to our researchers 
apparently being treated as part of the story no matter how they explained themselves. This extended to players continuing to visit one of the researchers in their office at the University after that game had finished. Whether these players genuinely believed us (as researchers) to be part of the plot or whether they were being playful is beside the point. In either case, it becomes challenging to reason about informed consent in a situation where participants claim to believe that researchers are part of a fiction. Seen another way, the participants are now challenging and deconstructing the researchers' own frames of reference and boundaries; the researchers being, thereby, hoisted by their own (or the artist's) petard.

However, critical reaction and audience dialogue are part and parcel of the reception of cultural experiences, which raises opportunities for engaging audiences in ethical discussions after the experience. Rather than treating participants as experimental 'subjects' to be studied impersonally, it might better to actively engage them in making and possibly publishing their own interpretations of an experience as part of its overall critical reception, for example blogging their experience or writing and commenting on reviews. However, there is the possibility that these blogs and reviews may refer to other participants, compromising attempts to maintain privacy and anonymity. In short, as audience members are increasingly encouraged to become active performers, so we need to consider whether they will inevitably enter a more public sphere in which their 'performances' are discussed and reviewed - perhaps critically.

\section{Withdrawal}

The principle of consent comes with an associated principle - that of withdrawal whereby a participant in a procedure can choose to withdraw their consent and disengage. While withdrawal is part of the ethical framework of many experimental procedures, there are of course points 
beyond which it may be difficult to fully withdraw in practice, for example the point after which an experimental drug has been administered. The same is true of some cultural experiences, although with nuanced differences in practice. While it is theoretically possible to withdraw from a traditional theatrical performance by standing up and leaving halfway through (and such walkouts certainly do occur, sometimes as an overt signal of a critical reaction), our example experiences include cases where withdrawal was difficult if not impossible. Perhaps the most obvious examples are to be found in Walker's Thrill Experiments in which participants were strapped into rollercoasters and other large amusement rides. It is very difficult to stop such a ride once underway - impossible at some points - and so once strapped into their seats participants typically have to see the ride through. Indeed, irrevocably committing oneself to a scary ride experience may be an essential element of the thrill. Consequently, many riders will be scared at some point and are likely to communicate this externally as part of the natural performance of 'doing a ride'. This is natural territory for thrill rides, and operators may become skilled as distinguishing 'normal' levels of fear from extreme cases in which action must be taken, for example where the physical safety of riders is at risk.

However, extending the visibility of participants through broadcast and surveillance technologies such as Walker's personal telemetry systems introduces additional considerations. We noted earlier examples of a rider using a public channel to ask for a ride to be stopped on behalf of the person sitting next to her. In this case, through the circumstance of being given a public communication channel, this rider is put in the position of having to judge how scared another rider might be and whether action needs to be taken. Moreover, spectators now also become aware of the 
matter and so may also be morally implicated. Thus, the technology may disrupt traditional practices in which experienced ride operators 'turn a blind eye' to those that they feel are 'normally' scared and continue with the ride anyway. The vicarious nature of performances where technology enables one participant to gain an unusually close up view of another's experience, especially where they are well-known or dear to them, raises ethical complications around withdrawal. In the Saw Alive example above it was the daughter watching from outside the horror maze who appeared to experience the greatest fear (on behalf of her mother who was inside) and who requested that her mother be withdrawn. This raises the question of how we might withdraw the spectator (daughter) as well as the primary participant (mother) from such an experience.

The consequences of withdrawal also need to be considered. All of the experiences that we have described include a social element, either because the experience is naturally undertaken in groups or because the technology makes some participants' actions unusually visible to others. Withdrawing from them may therefore involve a significant loss of face, especially when it is publicly visible or necessitates spoiling the experience for others (as might be the case when stopping an amusement ride to let someone off). Consequently, there is a tradeoff to consider between the short-term effects of feeling scared which might quickly pass into feelings of elation versus the possible humiliation of having withdrawn that might linger. A key challenge for managing withdrawal therefore lies in judging this balance. Another may lie in designing facesaving ways of withdrawing, for example removing participants from an experience 'at no fault of their own', perhaps through an apparent technical fault perhaps. 
While we have chosen thrill rides as perhaps the most obvious example of the challenges of managing withdrawal, the issue also arises in other examples. Urban Angel described a situation in The Malthusian Paradox in which they discovered that a player who they were interrogating was under their specified age limit, requiring them to negotiate withdrawal from the game in a way that saved face. Participants who are confused and isolated while exploring the streets of a city in Uncle Roy All Around You may not be able to immediately withdraw from the experience without significant assistance to find their way back.

Finally on this topic, we note that several experiences explicitly offered participants opportunities to withdraw at key points as a deliberate performance tactic in its own right. The Oblivion rollercoaster that featured in Walker's thrill experiments has signs at various points along the queue line advising prospective riders that they can still turn back. Blast Theory's Ulrike and Eamon Compliant also directly asks participants to signal if they wish to proceed further at one point. Such warnings can be theatrical devices aimed at raising the stakes and increasing tension as much as genuine attempts to manage withdrawal. Again, we see how the theatrical framing of these performances can challenge overt attempts to import established approaches from research ethics.

\section{Dealing with data}

Our example experiences also highlighted various ethical challenges arising from the use of both personal and scientific data including digital trails of who was present in a performance and what they did, close-up video and audio recordings of personal experiences, various kinds of sensor data including GPS positions, biodata and environmental measurements and historic climate data. 
The capture, analysis and use of personal data is a topic of growing public concern, not least through media coverage of the PRISM programme in which national security organisations appear to have gathered and analysed large volumes of citizens' personal data via the Internet. In turn, campaign organisations have argued that personal data needs to be treated in a more open and transparent manner (Liberty 2013). The ethical treatment of personal data, especially with regard privacy and consent, has also increasingly come into focus within HCI, with researchers arguing for more 'dynamic' and 'dialetic' approaches to privacy in general (Palen and Dourish 2003) and with privacy of personal data being the driving focus for discussions of consent considered above (Luger, Moran and Rodden 2013).

The appropriate treatment of personal data has long been recognised as an essential component of research ethics, with researchers considering how and where data is securely stored, its anonymisation at various stages of the research process from capture to publication, giving participants the right to review their personal data, and finally the deletion of data after the research has concluded. Somewhat in contrast is the recent movement towards open data (Shadbolt et al 2012), in which research datasets are published online. While this practice may have originated in scientific research, it is now being considered in other areas and also increasingly finding its way into public life, for example government services.

The capture and use of personal data, and especially explorations of privacy and surveillance, are prime territory for artists, providing a rich vein of material for artworks. Considering our illustrative examples, Uncle Roy All Around You was a conscious attempt to highlight what was seen as a growing surveillance culture post 9/11, while Walker's various thrill experiments revolve around the public display of what might be 
considered to be intimate personal data. Thus, artistic works may set out deliberately to challenge established ethical conventions around the use of personal data and indeed more generally around privacy, for example where participants are encouraged to adopt unusually close-up views of others, often without being seen themselves. In some cases, these transgressions are a way of explicitly foregrounding the artists' own concerns over privacy. In others they provide a powerful mechanism for creating frisson in their works. Either case challenges conventional approaches to handling data under research ethics.

We return to the concept of a performance frame to help us consider the different visibilities that personal data might have. In some cases data may only be revealed to its subjects (and the artists) as in Walker's Oblivion: Thrill Laboratory experience in which riders' own data was discussed with them in personal debriefing sessions. More commonly, data is revealed to audiences who are within the performance frame as is the case with experiments to broadcast biodata to spectators, or in Blast Theory's Can You See Me Now? and Uncle Roy All Around You in which players track others' locations, or Ulrike and Eamon Compliant in which participants leaving the interview room get to look back though a one way mirror at the participant following them. Interestingly, even though relationships between particular participants may not be symmetrical, with one voyeuristically observing another, a general sense of symmetry is often preserved in which participants may both be observers and observed at different points. A different level of challenge may emerge when personal data is made available outside the immediate performance frame, for example being published online or in a way that endures beyond the moment of the performance. 
Studying performances as part of HCI research introduces the idea that data might also be captured and used for research purposes as well as performance purposes. Researchers may capture additional data such as field notes and videos of participants engaging in the performance or may take the existing data produced by a performance into a quite different context, including publishing it as part of research papers and presentations. Consequently, researchers still need to consider the treatment of personal data for research purposes separate from its use within the performance itself, and should recognize that participants may have different views about its use in this new context.

A different dilemma concerns unexpected insights that might arise from the display and analysis of personal data. There were extensive discussions in Walker's Thrill projects around whether displaying heart rate data might potentially reveal health problems (e.g., to a knowledgeable expert such as a medical practitioner in the audience) and, if so, what should the artists and/or researchers do about this. While such insights might arise during the performance (perhaps the knowledgeable audience member might spot an abnormality) it is perhaps more likely to occur during any research analysis when there may be a longer-term and more systematic inspection of the data, perhaps even by researchers with medical expertise, for example, on the psychological interpretation of biodata.

A powerful dilemma arose in Blast Theory's work Ivy4Evr where there was an instance of a young person sending the fictional character Ivy a message in which they said that they were going to commit suicide. Following some debate, the artists decided to retrieve this participant's phone number from the system and send them a direct message with the contact details of the Samaritans charity. It transpired (from a return text message) that this participant was pushing the boundaries of gameplay 
rather than feeling genuinely suicidal; they were clearly embarrassed and apologetic about having sent the original message.

Our final data-related issue concerns the veracity of data. In Active Ingredient's A Conversation Between Trees a dilemma arose due to the unreliability of transmitting live sensor data from trees in Brazil to venues in the UK (Jacobs et al 2013). After deliberation, the artists decided to cover such gaps by replaying previously recorded data as if live, judging that the strict liveness of the data was less important than giving visitors an experience of some data during their time with the exhibit. A similar issue arose when Walker's thrill team worked with TBWA on the Nissan Juke campaign where visualisations of biodata were composited with video footage of participants. In this case, biodata from one moment in time was set against video footage from another (the biodata was for the depicted individual, but was time-shifted) in order to serve the needs of the story being told. Both cases reveal a degree of artistic license in the treatment of 'live' or 'as live' data in relation to the demands to deliver an experience to participants or tell a coherent story.

\section{Integrity}

These questions around the artistic treatment of scientific data segue into our final challenge, that of the wider question of 'integrity', a subject that was raised by several participants at our workshop. Artists stressed the crucial importance of maintaining artistic integrity to themselves as artists, to their audiences in terms of delivering to them a good experience, and to the wider materials and themes that they were addressing. On the other hand, researchers also stressed the importance of integrity with respect to their own research processes. Interesting ethical challenges then arose when these two senses of integrity came into tension. 
The first, as already discussed, arose from managing the liveness of data in terms of various compromises between delivering an experience to the audience (artistic integrity) versus maintaining the strict veracity of the data (scientific research integrity). This issue was debated at length for $A$ Conversation Between Trees because the issue of the scientific integrity of environmental and climate data is part of a highly contended public debate and also because a climate scientist from the UK Meteorological Office was playing an advisory role in the project. Given the contention around climate science it was important to take into consideration how issues of scientific integrity related to the artwork.

The issue of scientific integrity also arose when considering the interpretation of data in various projects. Artistic interpretations of levels of thrill from biodata (including the definition of various 'thrill factors') while grounded in psychological and physiological literature were not scientifically validated and the thrill 'experiments' were not controlled scientific experiments, even though they were clearly framed as experiments. Scientific integrity came into focus in a different way in The Malthusian Paradox whose narrative revolved around a fictional scientific conspiracy. These examples raised the question of institutional risk to the university partner in terms of potential confusion between artistic interpretations and performances and the institution's wider scientific research. We have already seen how this manifested in The Malthusian Paradox where participants chose to treat the HCI researchers as being part of the game rather than as observers who were standing back from it. The HCI researchers on the project also saw potential risk concerning the reputations of other scientific colleagues at their university. This was perhaps exacerbated by an ongoing confusion surrounding their role as HCI researchers and their frequent portrayal as 'scientists'; the research 
team was commonly referred to as 'scientists' by the artists and also by the press who appear to use the term as a catch all for technologically-oriented university researchers. However, they saw a clear distinction between themselves as HCI researchers who were involved in the study of interactive performances and other colleagues who might be working in the areas of the psychology and physiology of emotion or environmental and climate science. Thus, the question of scientific integrity involved the balancing of two distinct perspectives, HCI research and the underlying science that was being drawn on portrayed in the various performances, a distinction that was all too easily lost on others.

Workshop participants also highlighted various aspects of artistic integrity as important considerations. First was integrity to their audiences. This demanded delivering audiences a quality experience as already noted, but also involved engaging with them in an appropriately respectful way. For example, one artist reported feeling uncomfortable when directly interacting with participants who were clearly highly emotionally and personally involved in the experience while they themselves were an actor playing a role. Artists also stressed the importance of integrity to the themes and materials they were working with and to their own artistic freedom of expression. As with researchers, there was a question of institutional risk here. Some reported having been directly challenged by fellow members of the artistic community as to their involvement with research organisations who were seen as part of the establishment and who might be creating the very technologies (e.g., surveillance) against which the artists might be taking a stand. Put more simply, artists were mindful that collaborating with researchers could easily be seen as 'selling out' especially given the breadth of university engagements with all manner of industrial and even military partners - so that it was important that the 
integrity of the artworks should not be compromised, for example being made less provocative or transgressive, and that artists should consider wider reputational risks in engaging with the research establishment.

\section{DISCUSSION}

Having considered some specific ethical challenges arising from HCI's turn to the cultural, we finish our paper by broadening our discussion to address two wider themes: the notion of there being overlapping ethical frames, and the idea of engaging in ethical discussions throughout, including after, performances not only before them. These themes suggest the beginnings of a research agenda for HCI that may be framed by concerns in Responsible Research and Innovation

\section{Multiple and overlapping ethical frames}

It is illuminating to consider the ethical tensions between artistic practice and HCI (and sometimes science) research in terms of performances sitting within several distinct, but overlapping 'frames'. A performance frame, as previously discussed within HCI (Benford et al 2006), delineates a boundary between the performance and the wider world within which it takes place. A performance frame defines a context within which a performance can be interpreted; those inside the frame, be they performers, producers, technical crew or audience members, are aware that a performance is taking place and are able bring to bear a set of expectations as to how to interpret the events that unfold, for example 'willingly suspending disbelief'. Those outside the performance on the other hand are unwitting bystanders (Sheridan 2007); although they may witness, or even be involved in, events they are not in a position to interpret them. Indeed, they may not recognise that a performance is taking place at all. While conventional western theatrical performances tend to be 
clearly framed, taking place inside a theatre, with the lights 'going down' as the performance begins and with the actors separated from the audience by a proscenium arch, contemporary theatre has explored more unusual and experimental framings, for example promenade theatre in which actors intermingle with the general public in everyday public spaces, a trend that is well suited to the use of interactive and especially mobile technologies as revealed by many of the projects described above.

We argue that performances that are part of research projects are simultaneously placed within and contextualised by a second frame, an HCI research frame, that contains those people who engage in the research and defines how these people are able to interpret events as research. The epistemological and methodological stance of the researchers will then determine how they relate to the various participants within this frame and will guide ethical choices, for example, whether the performance is seen as part of an experiment or whether it is the subject of an ethnographic study of a natural phenomenon.

One source of ethical tensions arises from the opposing characteristics of these different frames. Artists' ethical concerns may focus on the artistic integrity of the work and their own freedom of self-expression. Where they are concerned with broader ethical challenges such as privacy, the ethics of warfare, or climate change, their approach may be deliberately transgressive, pushing back at the established moral order and provoking debate and discussion. They may positively embrace risk taking and also seek to pass on a degree of ethical responsibility to audience members who become responsible for their own conduct within the performance. Finally, artists appreciate and often exploit 'blurry' frames in which the lines between the performance and the everyday world become confusing and difficult to interpret. 
Research ethics, especially those grounded in the experimental tradition, tend to be more conservative. While they may certainly involve risk the aim is very much to minimse this. There is an emphasis on planning beforehand, identifying and resolving ethical dilemmas before conducting an experiment, and defining the frame of the experiment as clearly as possible. While tactics of surprise and deception may certainly be involved, for example in psychological experiments, they are seen as potentially problematic techniques to be treated with a degree of caution rather than as a core element of the experience that may be embraced. Finally, at risk of generalization, experimental subjects are not given great agency in the design of the experiment, nor are they greatly involved in the discussion of ethical concerns, either beforehand of afterwards.

Our paper has revealed how further ethical tensions arise from various ways in which these different frames may overlap. Researchers may become involved in the performance frame as developers of the work. Rather than observing the work from the outside and so being able to distance themselves from the artists to a degree, much as ethnographers may separate themselves from the people they observe (albeit sometimes with a degree of difficulty), the researchers become involved in making the work and so assume a degree of responsibility for the work itself as well as for the ethics of how it is studied.

As an extension of this, researchers may sometimes appear 'on stage', directly engaging audience members, including acting as publicly visible technicians who brief participants or directly engage with them to fix technical problems. This approach, in which the artist-researcher performs within the work itself and then reflects on this has been described as 'designing from within' (Taylor et al 2011). 
Even if this is not the case, artists may implicate researchers in the performance, suggesting that they are part of the performance as most clearly seen in The Malthusian Paradox. This latter situation can profoundly complicate the ethical situation as participants may struggle to distinguish research ethics processes from the world of performance so that issues of consent, withdrawal and privacy become very difficult to manage, especially if participants themselves begin to playfully take control as discussed above.

In their turn, artists may become involved in the research frame. In the above projects, artists' names have often appeared on scientific papers (as indeed they do on this one). Others have become partners in collaborative research projects funded by agencies such as the European Union or UK Technology Strategy Broad. Yet others have taken up fellowships within research groups such as the Mixed Reality Laboratory, while others such as Jacobs have gone on to undertake HCI-related PhDs where they conduct HCI studies in parallel to or even integrated within an artwork or performance.

In short, not only is there an inherent tension between research and artistic ethical frames, but this is complicated by an increasing blurring between them - in both directions.

What might we do about this? At the very least we need to acknowledge the existence of multiple frames and try to be clear about the implications of each for our ethical reasoning. In their turn, ethical bodies such as institutional Ethics Committees and Institutional Review Boards will also need to recognise and be sensitive to these different frames, for example taking on additional expertise - research ethics committees and IRBs may need to include members with experience in delivering artistic 
performances while venues, curators, producers and artists themselves may wish to seek advice on research ethics.

\section{Doing ethics throughout - including 'on the way out'}

This brings us to our final general point concerning the extent to which, (and when and how) we involve audiences in ethical matters arising from interactive performances.

At risk of generalization, we would argue that research experiments tend not to engage their participants in protracted ethical debates. There is of course some involvement: ethical issues are raised at the point of consent, participants are often provided with a contact point for raising any concerns they may subsequently have; public, community and other 'user' representatives may sit on advisory and review boards, and the wider public has a voice through the media. However, researchers rarely set out to engage their participants in a detailed ethical discussion around a particular experiment or study, either beforehand or afterwards, let alone deliberately provoke an ethical debate with them. Rather, we suspect that that ethics may often be seen as a process of managing risk to institutional reputation in which it is simplest to minimise any public fuss around ethics. Researchers, in general, do not set out to deliberately provoke ethical debate or court controversy. Some artists on the other hand, most clearly do.

Given the inevitable tensions that this raises, HCI researchers (and their institutions) who enter this space may wish to consider an alternative strategy, one suggested by the approach of RRI, that of proactively engaging participants in ethical debates and critical dialogue around artworks as part of the research. Moreover, this might be seen as an ongoing process that unfolds throughout the entire process, from the initial design of performances and associated studies, through negotiating 
boundaries during a performance itself, to actively fostering public debate afterwards. Such an approach mirrors previous proposals for how to manage consent as an ongoing process in ubicomp research (Luger and Rodden 2013), extending it to address a wider range of ethical concerns while also emphasizing the importance of discussion after the fact which we believe to be particularly appropriate to cultural experiences.

Of course, it will still remain important to consider ethical challenges in advance of a performance, exploring and clarifying the ethical frames of the different stakeholders, balancing potential benefits and costs/risks of design choices, and engaging with research and professional processes such as legal compliance, risk assessments, and frameworks for handling personal data. Having said this, we also emphasise the importance of establishing appropriate expertise and processes for negotiating ethical issues such as consent, withdrawal and the treatment of personal data as the experience unfolds. We then particularly stress the possibilities for actively promoting the discussion of ethical issues with audiences after their experience and to provide appropriate forums for this such as support for blogs, reviews, panels, workshops, interviews and so forth. The key is to shift the scope of the ethical debate from taking place in a closed forum such as an ethics committee before the event to instead open it up to far wider involvement after the event. As an aside, note that we are not arguing for a form of participatory design here; while some artists may pursue participatory approaches, our experience is that works tend to be created by artists according to their own vision and drive. We are, however, arguing for giving participants a clear voice.

There is one important proviso however. The general degree of risk in such performances should be relatively small compared to say the risks of medical experiments. In particular, risks of causing offense and emotional 
trauma should not spill out of the performance frame wherever possible and there should be very low levels of long-term risk to participants' wellbeing. We believe that this will often be the case - and was the case in all of our documented examples - although note potential exceptions such as when artists engage with medical technologies and procedures. The management of risk is still required of course, but is perhaps best dealt with through professional institutions such as venues and curators who have an extensive experience of judging the ethical line with public artworks. In other words, where the artworks fall within broadly normal limits, researchers may wish to rely on the experience of professionals to ascertain whether an artwork lies within the limits of legality and public acceptability (but not necessarily without controversy) and then ensure that audience voices are heard in ethical discussions after the event. This is one of the great benefits of working with professional artists and the professional art world that they belong too. Equally, it is perhaps the greatest risk of working with untried artists or of researchers acting as artists themselves.

To summarise, we propose affording a degree of freedom and flexibility for artists and researchers to create experimental performances that push the boundaries of experience and ethical positions providing that:

(i) these are circumscribed by research and artistic performance frameworks that embody a set of best practices and risk mitigation for inherently low risk experiences (i.e. comparable in risk to everyday life).

(ii) they encourage audiences to have a voice in the ethical discussion. 
Research ethics might then place less emphasis on minisiming ethical risk beforehand and more on negotiating ethical issues throughout and on maximising participation in ethical debate afterwards. Those proposing the creation and study of performances might be invited to explicitly state how they will foster and document such debate.

Whilst there is a strong recognition that risk needs to be managed and ethical issues surfaced, there is considerable debate about the extent to which the biomedical paradigm can be applied to HCI, or perhaps even to ICT research more widely. Instead, when seen through the lens of RRI, we emphasise the importance of reflecting on the purposes of, motivations for and potential implications of the research, and the associated uncertainties, areas of ignorance, assumptions, framings, questions, dilemmas and social transformations these may bring. The RRI approach also stresses the importance of establishing broader public engagement. Participation allows for feedback on the research itself, the process and the purpose. It can increase the legitimacy of findings, broaden the knowledge base and enrich the research. Public engagement here goes beyond increasing the public understanding of science (even though this is a legitimate aspect of it) and creates a two-way communication between researchers and the public. It encourages researchers to be flexible and responsive to the ways in which a project may unfold and to re-evaluate and, where necessary, recalibrate the vision of the research and, consequently, the research approach.

\section{CONCLUSION}

In this paper we have begun to frame an agenda for HCI's consideration of the ethical challenges arising from creating and studying interactive performances. This has been motivated by a combination of HCI's turn to the cultural, coupled with its increasing engagement with research ethics. 
We have shown that ethics in HCI and the arts draw on different traditions leading to differing interpretations and practices that may not always be compatible.

We therefore turned to the approach of RRI s a way of transcending these ethical traditions and seeking out practical ways of dealing with their competing demands. We used the AREA framework to inform our use of RRI. Specifically, staging the workshop described above enabled us to engage with key stakeholders. This entailed a reflection on the problem that allowed us to chart six key ethical challenges for interactive art projects that also serve as research projects.

1. Transgression - dealing with the inherently transgressive nature of performances that may adopt provocative positions on topical ethical questions and require participants to take on significant moral agency for the impact of their actions.

2. Boundaries - understanding how interactive performances blur traditional boundaries, especially the key boundary of the performance frame that separates audience members who are able to interpret the events they witness as a performance from unwitting bystanders who may not be able to do so. Artists use their professional judgement to negotiate such boundaries on an ongoing basis.

3. Consent - the core ethical principle of consent works very differently in the kinds of performances we have considered. While marketing and ticketing may communicate something of the nature of a performance in advance, many of the details often remain hidden and explicit consent is rarely sought.

4. Withdrawal - while participants should be able to exercise their right to walk out of an experience at any time, this can be difficult in some circumstances (e.g., amusement rides once underway) and performers 
need to carefully balance the immediate versus long-term consequences of withdrawal.

5. Data - from physiological biodata to environmental sensing, the capture and display of data is providing rich material for performers. Breaching the traditional ethical concern of privacy provides fertile artistic ground for creating unusual and provocative experiences, but may be especially problematic if it reaches out beyond the performance frame.

6. Integrity - artists and researchers both have a strong sense of integrity where their professional practices are concerned. For artists, this involves integrity to their material, the need deliver a good experience to their audience, and maintaining their own creative freedom of expression. For researchers, this means adhering to research codes of ethics and sometimes raises questions about the treatment of scientific data or even the broader portrayal of 'science' within performances.

Beyond these specific challenges, we have offered two wider reflections. The first concerns the idea that the kinds of performance that we have describe can be interpreted through multiple frames, and in particular through performance and HCI research frames, each of which may bring a distinctive ethical perspective. Ethical tensions arise when these frames only partially overlap (i.e., address some non-mutual concerns), pull in opposing directions, or when they become blurred as artists are seen as, or even become, HCI researchers and vice versa. The second proposes that ethical issues need to be negotiated throughout an experience and also discussed afterwards. 
We close by considering two final questions: what are the implications of our findings for HCI's engagement with the cultural? And what are their implications for HCI's wider discussion of values and ethics?

The immediate implications for HCl's turn to the cultural

Our findings are most immediately relevant to $\mathrm{HCI}$ 's growing engagement with cultural applications and especially to projects that combine artistic practice with HCI research. Looking back on our six key challenges, some are relatively unfamiliar to HCI, most notably considerations of transgressions and boundaries, and so our contribution here is to highlight these as important new concerns. The remaining four consent, withdrawal, data and integrity - are already familiar and so our contribution here is to encourage HCI researchers, and their artistic partners, to consider them in a new light. Experience suggests that those embarking in culturally-oriented HCI research need to consider how these issues apply to their specific projects. Moreover, we suggest that ethics committees and institutional review boards will also need to be familiar with the specific issues and professional artistic practices involved if there are to make appropriate judgements, rather than trying to assess such projects from within the frame of conventional experimental ethics. While our paper serves to highlight some initial challenges and ground them in a portfolio of examples, this is just a start, and a further challenge is for the emerging arts-HCI community to establish appropriate forums for discussing issues and sharing examples and best practice.

Wider implications for discussions of values and ethics within $\mathrm{HCl}$

It is also informative, if more speculative, to consider the implications of our findings for mainstream HCI in the light of the literature on ethics and values that we discussed earlier. Beyond highlighting new ethical 
challenges or suggesting new treatments of familiar ones as already discussed, our paper points towards some significant differences in underlying values. In exploring Value Sensitive Design, Friedman and Khan (2003) listed some specific values with 'ethical import' for HCI including: human welfare, privacy, trust, autonomy, freedom from bias, informed consent, accountability, identity, calmness, ownership and property, universal usability and environmental sustainability. In discussing whether HCI can adopt universal values or alternatively should adopt a position of cultural relativism, Borning and Muller (2012) argued for a pluralistic approach in which such lists of values are associated with the particular cultures and viewpoints within which they were developed. They also stress the importance of establishing a wider range of case studies.

Our paper offers such a case study. The ethical challenges that we have highlighted above are strongly grounded in the values of self-expression and freedom of speech, core values that underlie artists' desire to express themselves creatively and challenge established thinking, values that lie at the heart of the notion of artistic integrity. These values and their particular ethical import have not been widely considered in HCI to date. Moreover, it is easy to see how they may clash with other values, for example with privacy as we discussed earlier. We have also revealed something of the culture within which these values have been developed, specifically how artistic projects belonging to recognisable artworlds are already governed by existing professional ethical practices and structures. HCI needs to recognize, understand and respect these practices and structures if it is to collaborate with cultural practitioners as much as it needs to understand medical values and ethical practices if it is to collaborate with medical practitioners. 
The final contribution of our paper lies in highlighting the potential of the RRI approach to help manage these tensions. We believe that this paper represents an important practical example of how RRI can help identify and conceptualise issues related to ethical and social acceptability and desirability in research and technology development. It is clear, however, that this paper can only be one part of the RRI approach. We have spent considerable effort on two of the four aspects of RRI, namely engagement and reflection. More remains to be done in the other two, namely anticipation and action. Anticipation requires scholars to methodically explore possible and likely outcomes of their work. For this, such anticipation could mean to explore and possibly experiment with the use of different ethical frames in performances as well as HCI research. Is it possible to find hybrid ethics or new ethical approaches that satisfy both traditions? How could these be practiced and what effect could this have on the component fields? In the light of the specific six challenges that emerged from reflection, we might explore the implications of integrating them as experienced by performers into an HCI design process - so for example, we might ask if all HCI researchers should consider the nature of transgression in their designs? Such questions of anticipation of possible consequences, fallible though they are, constitute an important aspect of RRI. Action is the next step - once the community has a clear understanding of what the issues are then perhaps a foresight analysis could be undertaken of the impact on HCI practices - for example, would the structure of ethical review boards need to be altered? Might we need experienced curators as part of the design process or as part of the review boards?

The aim of our paper has been to highlight key ethical challenges that arise as HCI increasingly engages with performance, and possibly other, 
artistic practices with the intention of enabling artists and researchers to engage with their respective ethical processes. We are sure that we have not addressed all of the ethical issues that arise from HCI's turn to the cultural - we have highlighted those that arose from a reflection on practice at a unique interdisciplinary workshop. Nor have we offered concrete guidelines addressing specific 'dos and don'ts'. Instead our aim has been to open up the debate and lay some foundations for a practical engagement with ethical matters, grounded in the approach of Responsible Research Innovation, as well as establishing a platform for further research on this increasingly important topic. Such further research and proposals of practical ways forward are required to provide the actionable insights that will allow future researchers to reap the benefits of the cultural turn of HCI while ensuring acceptability of their practices and outputs.

\section{ACKNOWLEDGEMENTS}

We gratefully acknowledge the support of the artists who have collaborated with us to make the various artworks that we describe here, namely Active Ingredient, Blast Theory, Brendan Walker and Urban Angel. We thank Blast Theory for organizing and hosting Act Otherwise and also the many participants who attended and engaged so enthusiastically in discussions. This work was funded by RCUK through the Horizon Digital Economy Research grant (EP/G065802/1), by the Engineering and Physical Sciences Research Council (EPSRC) through Steve Benford's Dream Fellowship (P/J005215/1) and by the Engineering and Physical Sciences Research Council (EPSRC) through the Framework for Responsible Research and Innovation project grant (EP/J000019/1). 


\section{REFERENCES}

ACM (2013) ACM Code of Ethics and Professional Conduct, http://www.acm.org/about/code-of-ethics 2013, ACM, Verified August 2013

Anderson, B and Jirotka, M (forthcoming) Ethical Praxis in e-Research in P. Halfpenny and R. Procter (forthcoming) Innovations in Digital Methodologies. Sage

Anderson, S., Bredeche, N., Eiben, A.E., Kampis, G. and van Steen, M. (2013). Herding Black Sheep Adaptive Collective Systems, on-line book publication available from http://focas.eu/adaptive-collective-systems/ (Verified July 2014)

Annas, G., Grodin. M. (1995) The Nazi Doctors and the Nuremberg Code: Human Rights in Human Experimentation, Oxford University Press; New Ed edition

Bauman, Z. 2008. The Art of Life (Polity Press)

Becker, Howard S. 1982. Art Worlds (Univ of California Press)

Benford, S., Crabtree, A., Reeves, S., Sheridan, J., Dix, A., Flintham, M., and Drozd, A. (2006) The Frame of the Game: Blurring the Boundary between Fiction and Reality in Mobile Experiences. In Proceedings of the SIGCHI conference on Human Factors in computing systems (CHI '06), ACM, New York, NY, USA, 427-436.

Benford, S., Giannachi, G. (2011) Performing Mixed Reality, MIT Press.

Benford, S., Greenhalgh, C., Crabtree, A., Flintham, M., Walker, B., Marshall, J., Koleva, B., Rennick Egglestone, S., Giannachi, G., Adams, M., Tandavanitj, N., and Row Farr, J. 2013. Performance-Led Research in the Wild. ACM Trans. Comput.-Hum. Interact. 20, 3, Article 14 (July 2013), 22 pages. 
Benford, S., Greenhalgh, C., Giannachi, G., Walker, B., Marshall, J, Rodden, T. (2012) Uncomfortable Interactions, In Proceedings of the SIGCHI conference on Human Factors in computing systems (CHI '12), Austin, Texas, May 2012, ACM

Blast Theory (2013), Act Otherwise, workshop webpage and agenda, http://www.blasttheory.co.uk/bt/event_actotherwise2013.html

Blythe, M., Overbeeke, K., Monk A., Wright, P., 2004, Funology: From Usability to Enjoyment, Kluwer

Borning, A. \& Muller, M. Next steps for value sensitive design. In Proceedings of the SIGCHI conference on Human Factors in computing systems (CHI '12), ACM Press (2012), 1125-1134.

Boulton, Mary, and Michael Parker. 2006, "Informed consent in a changing environment." Social Science \& Medicine 65.11, 2187-2198.

Cairns, Paul, and Harold Thimbleby (2003) "The diversity and ethics of HCI." Computer and Information Science 1.212 (2003): 1-19.

Cockton, G. 2004, Value-Centred HCI. In Proceedings of the third Nordic conference on Human-computer interaction, Tampere, Finland.

Danto, A., 1964, 'The Artworld', The Journal of Philosophy, 571-84

Denzin, N. (1997). Interpretive ethnography: Ethnographic practices for the 21st century. London: Sage.

Dickie, G, 1974, 'Art and the Aesthetic: an Institutional Analysis', Cornell University Press.

DiSalvo, C., Boehner, K., Knouf, N. and Sengers, P., (2009) Nourishing the Ground for Sustainable HCI: considerations from ecologically engaged art, In Proceedings of the SIGCHI conference on Human Factors in computing systems (CHI '09), 385-394, ACM, 2009. 
Edwards, R., \& Mauthner, M. (2002). Ethics and feminist research: Theory and practice. In M. Mauthner, M. Birch, J. Jessop, \& T. Miller (Eds.), Ethics in qualitative research. London: Sage.

Ehn, P. (1990) Work-Oriented Design of Computer Artifacts. Lawrence Erlbaum Associates.

England, D., Fantauzzacoffin, J. (2013) Digital Arts: Featured Community, $\quad$ CHI 2013 website, ACM http:/chi2013.acm.org/communities/digital-arts/

Evans, E., Flintham, M., Martingdale, S., (2013) The Malthusian Paradox: Performance in an Alternate Reality Game, Journal of Personal and Ubiquitous Computing, 2013.

Flanagan, M., Howe, D., and Nissenbaum, H. (2005) Values at play: Design tradeoffs in socially-oriented game design. In Proceedings of the SIGCHI conference on Human Factors in computing systems (CHI '05), ACM Press (2005), 751-760.

French, Lyndsay (2002) 'Exhibiting Terror', in Bradley, Mark and Petro, Patrice, (eds) Truth Claims: Representation and human rights, London: Rutgers University Press, pp. 131-56.

Friedman, B., and Kahn, P. H., (2003) Human values, ethics, and design. In J. A. Jacko and A. Sears (eds.), The Human-Computer Interaction Handbook, Mahwah Erlbaum, 1177-1201.

Gaver, W., Beaver, J., Benford, S. (2003) Ambiguity as a resource for design, In Proceedings of the SIGCHI conference on Human Factors in computing systems (CHI'03), 233-240, ACM

Goodall, J. (2005). An order of pure decision: Un-natural selection in the work of Stelarc and Orlan. In M. Featherstone (Ed.), Theory, Culture \& Society: Body modification. (pp. 149-171). London: SAGE Publications Ltd. doi: http://dx.doi.org/10.4135/9781446220207.n9 
Grimpe, Barbara, Mark Hartswood, and Marina Jirotka. (2014) "Towards a closer dialogue between policy and practice: responsible design in HCI." Proceedings of the 32nd annual ACM conference on Human factors in computing systems. ACM.

Guston, David H. (2014) "Understanding 'anticipatory governance'." Social Studies of Science 44.2 (2014): 218-242.

Hartswood, M and Jirotka, M (2013) Towards ethical governance of social machines

Jacobs, Janet (2008), 'Gender and Collective Memory: Women and Representation at Auschwitz', Memory Studies, 1:2. 211-25.

Jacobs, R., Benford, S., Selby, M., Golembewski, M., Price, D., Giannachi, G. 2013. A conversation between trees: what data feels like in the forest. In Proceedings of the SIGCHI Conference on Human Factors in Computing Systems (CHI'13). ACM, New York, NY, USA, 129-138.

Jones J. (1993) Bad Blood: Tuskegee Syphilis Experiment - A Tragedy of Race and Medicine, The Free Press, NY

Kent, J., Williamson, E., Goodenough, T., \& Ashcroft, R. (2002). 'Social science gets the ethics treatment: Research governance and ethical $\begin{array}{llll}\text { review. Sociological } & \text { Research }\end{array}$ www.socresonline.org.uk/7/4/williamson.html.

Knight, John. (2006) "Ethics and HCI." Encyclopedia of Human Computer Interaction (2006): 199

Knobel, C., Bowker, G. Values in design. Communications of the ACM 54, 7 (2011), 26-28.

Koleva, B., Taylor, I., Benford, S., Fraser, M., Greenhalgh, C., Schnadelbach, H., vom Lehn, D., Heath, C., Row-Farr, J., and Adams, M. (2001) Orchestrating a mixed reality performance. In Proceedings of the 
SIGCHI conference on Human factors in computing systems (CHI '01). ACM, New York, NY, USA, 38-45.

Lévinas, E. (1985) Ethics and Infinity: Conversations with Philippe Nemo. Trans. Richard A. Cohen, Pittsburgh, PA: Duquesne University Press.

Liberty, (2013) The Value of Our Digital Identity, Global Policy Series, available from http:/www.libertyglobal.com/PDF/public-policy/TheValue-of-Our-Digital-Identity.pdf (verified July 22nd 2014)

Luger, E., Moran, S., Rodden, T., (2013) Consent for all: revealing the hidden complexity of terms and conditions. In Proceedings of the SIGCHI Conference on Human Factors in Computing Systems (CHI '13). ACM, New York, NY, USA, 2687-2696.

Luger, E., Rodden, T., (2013) An informed view on consent for UbiComp. In Proceedings of the 2013 ACM international joint conference on Pervasive and ubiquitous computing (UbiComp '13). ACM, New York, NY, USA, 529-538.

Marshall, J., Rowland, D., Egglestone, S., Benford, S.,Walker, B., McAuley, D. (2011) Breath Control of Amusement Rides, In Proceedings of the 2012 ACM annual conference on Human Factors in Computing Systems (CHI'11), April 2011, ACM

McCarthy, J., Wright, P., (2004) Technology as Experience, MIT Press

McGonigal, J., (2011) Reality is Broken, Penguin Press, NY, USA.

McMillan, Donald, Alistair Morrison, and Matthew Chalmers. (2013) "Categorised ethical guidelines for large scale mobile HCI." Proceedings of the SIGCHI Conference on Human Factors in Computing Systems. ACM.

Morrison, A., Viller, S., Mitchell, P., 2011. Building sensitising terms to understand free-play in open-ended interactive art environments. In 
Proceedings of the SIGCHI Conference on Human Factors in Computing Systems (CHI'11). ACM, New York, NY, USA, 2335-2344

Mumford, E., (1995), Effective Systems Design and Requirements Analysis: the ETHICS Method, Macmillan

Murphy, E., Dingwall, R. (2001) The Ethics of Ethnography. In Atkinson, P., et al (eds.), Handbook of Ethnography, 339-351, Sage.

Oliver, Kelly (2001) Witnessing Beyond Recognition, Minneapolis: University of Minnesota Press.

Palen, L, Dourish, P., (2003) Unpacking “privacy" for a networked world, Proceedings of the SIGCHI Conference on Human Factors in Computing Systems CHI '03, Pages 129-136.

Pattullo, E. (1982). Modesty is the best policy: The federal role in social research. In T. Beauchamp, R. Faden, R. J. Wallace, \& Walters (Eds.), Ethical issues in social science research. (pp. 373-389). Baltimore: Johns Hopkins University Press

Reeves, S. (2011) Designing Interfaces in Public Settings, Springer

Reeves, S., Martingdale, S., Tennent, P., Benford, S., Marshall, J., Walker, B., "Telling Stories Using Biodata in Promotional Filmmaking”, submitted to ACM Transactions on CHI (currently accepted subject to minor revisions).

Ridout, N. (2009) Theatre and Ethics, Houndmills: Palgrave Macmillan.

Rifkin, F. (2010) The Ethics of Participatory Theatre in Higher Education, http://78.158.56.101/archive/palatine/files/ethics.pdf, verified 21/6/2013.

Schnädelbach, H., Egglestone, S. R., Reeves, S., Benford, S., Walker, B., Wright, M. (2008) Performing Thrill: Designing Telemetry Systems and Spectator Interfaces for Amusement Rides, In Proceedings of the 2008 
ACM annual conference on Human Factors in Computing Systems (CHI '08), Florence, Italy, ACM Proceedings, 1167-1176.

Sellen, A., Rogers, Y., Harper, R., and Rodden, T. (2009) Reflecting human values in a digital age. Communications of the ACM. 52, 358-366.

Sengers, P., Gaver, W. (2006) Staying open to interpretation: engaging multiple meanings in design and evaluation, Proceedings of Designing Interactive Systems (DIS '06), 99-108, ACM

Shadbolt, N., O'Hara, K., Berners-Lee, T., Gibbins, N., Glaser, H., Hall, W., Schraefel, M.C. (2012) Linked open government data: lessons from Data.gov.uk. IEEE Intelligent Systems, 27, (3), Spring Issue, 16-24.

Sheridan, J., Bryan-Kinns, N., Bayliss, A., 2007. Encouraging witting participation and performance in digital live art. In Proceedings of the 21st British HCI Group Annual Conference on People and Computers: HCI...but not as we know it - Volume 1 (BCS-HCI '07), Vol. 1. British Computer Society, Swindon, UK, UK, 13-23

Stilgoe, J., Owen, R., and Macnaghten, P . (2013) Developing a framework for responsible innovation. Research Policy, 42, 1568-1580.

Taylor, R., Schofield, G., Shearer, S., Wallace, J., Wright, P., Boulanger, P. and Olivier, P. (2011) Designing from within: humanaquarium. In Proceedings of the 2011 annual conference on Human factors in computing systems (CHI '11). ACM, New York, NY, USA, 1855-1864.

Tolmie, P., Benford, S., Flintham, M., Brundell, P., Adams, M., Tandavantij, N., Row Far, J., and Giannachi, G., (2012) "Act natural": instructions, compliance and accountability in ambulatory experiences. In Proceedings of the SIGCHI Conference on Human Factors in Computing Systems (CHI '12). ACM, New York, NY, USA, 1519-1528.

Von Schomberg, R. (2013) A vision of Responsible Research and Innovation. In Responsible Innovation: Managing the Responsible 
Emergence of Science and Innovation in Society, Owen, R., Bessant, J., and Heintz, M., ed., Wiley, Hoboken, 51-74.

Whittaker, E. (2005). Adjudicating entitlements: The emerging discourses of research ethics boards. Health, 9(4), 513-535.

Wiener, N. (1954) The Human Use of Human Beings. Da Capo Press,

Willett, J. (1993 [1957]) Brecht on Theatre, London: Methuen.

Zimbardo, P. G. (1973) On the ethics of intervention in human psychological research with special reference to the Stanford Prison Experiment, Cognition, 2, 243-256.

EPSRC. 2014. "Framework for Responsible Innovation - Engineering and Physical Sciences Research Council." September 10. http://www.epsrc.ac.uk/research/framework/.

European Commission. 2011. Commission's Recommendation to the Member States on Responsible Research and Innovation. European Commission.

http://ec.europa.eu/governance/impact/planned_ia/docs/2010_rtd_012_res ponsible_research_innovation_en.pdf.

Mason, P. 2012. Responsible Innovation Framework for Commercialisation of Research Findings. For Use in Synthetic Biology Feasibility Studies Competition 2012: Advancing the Industrial Application of Synthetic Biology. Technology Strategy Board.

Montola, Markus, Waern, Annika, Kuittinen, Jussi, and Stenros, Jakko (2006) 'Deliverable D5.5 Ethics of Pervasive Gaming', http://www.pervasive-gaming.org/Deliverables/D5.5-Ethics.pdf

Muniesa, F., and M. Lenglet. 2013. "Responsible Innovation in Finance: Directions and Implications." In Responsible Innovation, edited by R. Owen, M. Heintz, and J. Bessant. Chichester, UK: Wiley. 
NWO. 2010. "Responsible Innovation. Project Summaries." Netherlands Organisation for Scientific Research (NWO).

Owen, R., J. Stilgoe, P. Macnaghten, M. Gorman, E. Fisher, and David H. Guston. 2013. "A Framework for Responsible Innovation." In Responsible Innovation, edited by R. Owen, M. Heintz, and J. Bessant. Chichester, UK: Wiley.

RRI tools project. 2014. "RRI Tools." Accessed November 14. http://www.rri-tools.eu/.

Rogers, Y., HCI Theory: Classical, Modern and Contemporary, Morgan and Claypool, 2012

Simakova, E., and C. Coenen. 2013. "Visions, Hype and Expectations: A Place for Responsibility." In Responsible Innovation, edited by R. Owen, M. Heintz, and J. Bessant. Chichester, UK: Wiley.

Stahl, B.C. 2012. "Responsible Research and Innovation in Information Systems." European Journal of Information Systems, no. 21: 207-11. doi:10.1057/ejis.2012.19.

Stahl, B.C., G. Eden, and M. Jirotka. 2013. "Responsible Research and Innovation in Information and Communication Technology. Identifying and Engaging with the Ethical Implications of ICTs." In Responsible Innovation, edited by R. Owen, M. Heintz, and J. Bessant. Chichester, UK: Wiley.

Stahl, B.C., G. Eden, M. Jirotka, and M. Coeckelbergh. 2014. "From Computer Ethics to Responsible Research and Innovation in ICT." Information \& Management, February. doi:10.1016/j.im.2014.01.001. 


\section{AUTHOR STATEMENT}

This paper directly builds upon and extends two recent papers:

The first is: Benford, S., Greenhalgh, C., Crabtree, A., Flintham, M., Walker, B., Marshall, J., Koleva, B., Rennick Egglestone, S., Giannachi, G., Adams, M., Tandavanitj, N., and Row Farr, J. 2013. Performance-Led Research in the Wild. ACM Trans. Comput.Hum. Interact. 20, 3, Article 14 (July 2013), 22 pages. This paper reflected on our general methodology for working with artists to create and study interactive performances in the wild. The final section of this paper raised ethical issues as being a major challenge for future work. The paper that we are submitting here is our direct response to this having followed up with further new work.

The second is: Reeves, S., Martingdale, S., Tennent, P., Benford, S., Marshall, J., Walker, B., "Telling Stories Using Biodata in Promotional Filmmaking", submitted to $A C M$ Transactions on CHI (currently accepted subject to minor revisions). This paper focused on two recent examples of the work of one of the four artists discussed here - Walker discussing the issue of the 'data veracity' which is an issue we also discuss here. Veracity issue is just one of many ethical challenges that we cover here and we also expand our discussion of it to draw on other examples, most notably Active Ingredient's $A$ conversation Between Trees.

This paper explicitly references these two papers as well as other accounts of the performance works published at $\mathrm{CHI}$ and $\mathrm{CSCW}$ and in TCOHOI over many years.. However, in our opinion, the core work that we present in this submission - the major 'artists workshop', subsequent reflections, the six ethical challenges that we unpack, and the two broader issues that we raise at the end, all represent substantial new work. We also include significant new literature review material on Responsible research Innovation and performance ethics. Finally, we base our discussion of ethics on an extended range of performers, including those familiar to the CHI audience such as Blast Theory and Walker, and the relatively less familiar in the form of Active Ingredient and Urban Angel. 